\title{
Improving the Third Quadrant Operation of Superjunction MOSFETs by Using the Cascode Configuration
}

\author{
Juan Rodríguez ${ }^{1}$, Student Member, IEEE, Diego G. Lamar ${ }^{1}$, Member, IEEE, Jaume Roig ${ }^{2}$, Alberto \\ Rodríguez ${ }^{1}$, Member, IEEE, and Filip Bauwens ${ }^{2}$. \\ Departamento de Ingeniería Eléctrica, Electrónica, de Computadores y Sistemas, Universidad de Oviedo, Gijón \\ 33204, Spain \\ (e-mail: rodriguezmjuan@uniovi.es)
}

Power Technology Centre, Corporate R\&D, ON Semiconductor, Oudenaarde, Belgium

(e-mail: jaume.roig@onsemi.com)

\begin{abstract}
In this paper, the third quadrant behavior of a High-Voltage (HV) Superjunction MOSFET (SJ-FET) in Cascode Configuration (CC) with a Low-Voltage silicon MOSFET (LV-FET) is deeply studied by means of an analytical model and experimental data. The third quadrant dynamic behavior of the SJ-CCs is compared to the standalone counterparts by evaluating their reverse recovery time ( $\left.t_{R R}\right)$, reverse recovery peak current (IRRM) and reverse recovery charge $\left(Q_{R R}\right)$. An analytical model and experimental results show that the SJ-CC avoids or mitigates the activation of the SJ-FET body-diode during the third quadrant operation. As a consequence, the SJ-CC strongly improves the widely used Figure-of-Merit (FoM) $R_{O N} \cdot Q_{R R}$, which considers the on-state resistance of the transistors (RoN). In addition, the results obtained using a SJ-CC are similar or better than the achieved by SJ-FETs with enhanced reverse recovery (i.e., irradiated SJ-FETs). This paper also includes a comparison with commercial wide bandgap switches, concluding that the $R_{O N} \cdot Q_{R R}$ value provided by the SJ-CC is around eight times higher than the provided by a commercial GaN cascode.
\end{abstract}

Index Terms-Cascode configuration, Superjunction MOSFET, third quadrant, reverse conduction, reverse recovery charge $\left(Q_{R R}\right)$, synchronous rectification, silicon.

\section{INTRODUCTION}

$\mathrm{T}$ HE Superjunction MOSFET (SJ-FET) is one of the greatest contributions of the last 30 years in the power electronics field. This silicon-based technology, which was introduced in 1998 [1]-[3], offers lower on-state resistance $\left(\mathrm{R}_{\mathrm{ON}-\mathrm{HV}}\right)$, gate charge $\left(\mathrm{Q}_{\mathrm{G}-\mathrm{HV}}\right)$ and output charge (Qoss-HV) than traditional vertical MOSFETs. As a result, the SJ-FET has become the main High-Voltage (HV) power switching device for a voltage that ranges between $600 \mathrm{~V}$ and $900 \mathrm{~V}$.
Taking into account the SJ-FET qualities, its benefits mainly arises when it operates in first quadrant (i.e., the current flows from the drain to the source), and under hard-switching conditions. However, there are applications, such as synchronous DC-DC converters and inverters, where the power transistor operates in the third quadrant, also called reverse conduction (i.e., the current flows from the source to the drain). The technique in which these applications are based on is referred to as Synchronous Rectification (SR) and it consists in replacing diodes by transistors. Among other things, SR reduces conduction losses due to the low voltage drop in $\mathrm{R}_{\mathrm{ON}-\mathrm{HV}}$ in comparison to the forward voltage drop of a diode, and enables bidirectional power conversion.

The main problem is the poor performance of the SJ-FET body-diode, which jeopardizes the third quadrant operation [4]-[5]. The Reverse Recovery (RR) effect damages the performance of the power converter in terms of both power efficiency and Electromagnetic Interference (EMI). As a result, several techniques have been proposed to minimize the RR effect in order to enable the use of SJ-FETs in SR, taking advantage of their good switching behavior and low $\mathrm{R}_{\mathrm{ON}-\mathrm{HV}}$. Differently from the prior literature, a Cascode Configuration (CC) combining a SJ-FET and a Low-Voltage silicon MOSFET (LV-FET) to improve the RR (see Fig. 1) is proposed in this paper.

Nowadays, the CC is the preferred approach of some semiconductor companies to achieve normally-off $\mathrm{GaN}$ and $\mathrm{SiC}$ power transistors [6]-[10]. However, the CC has not been evaluated for silicon power switching devices until few years ago. The use of a SJ-FET in CC with a LV-FET (SJ-CC) was firstly proposed to reduce switching losses in [11]-[12]. A theoretical model of the switching mechanism during forward conduction of SJ-CCs paying especial attention to critical 


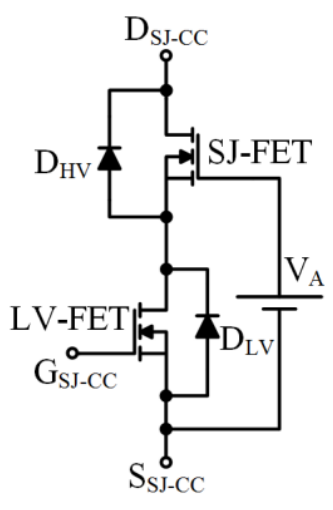

(a)

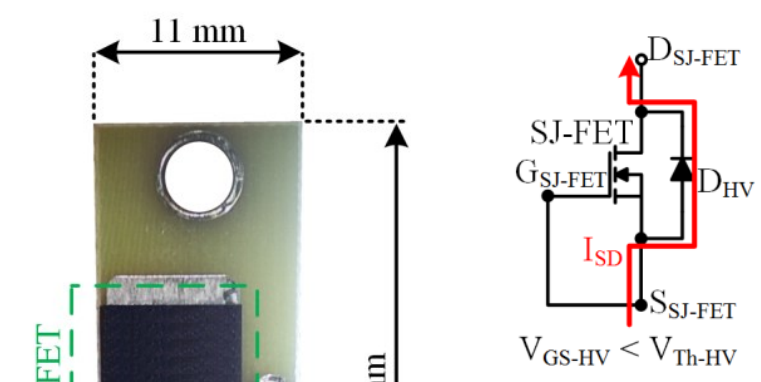

(a)

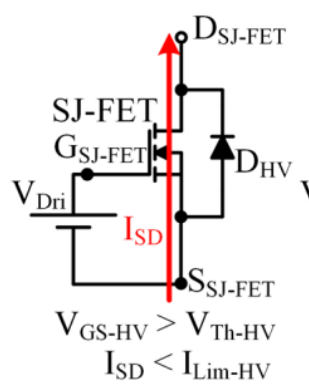

(b)

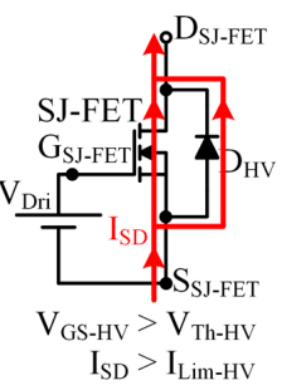

(c)

Fig. 2. Basic schematics of the SJ-FET in standalone configuration operating in third quadrant: (a) State A. (b) State B. (c) State C.

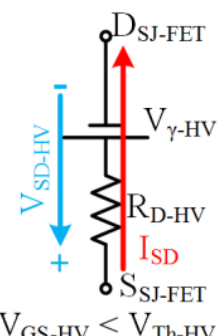

$\mathrm{V}_{\mathrm{GS}-\mathrm{HV}}<\mathrm{V}_{\mathrm{Th}-\mathrm{HV}}$

(a)

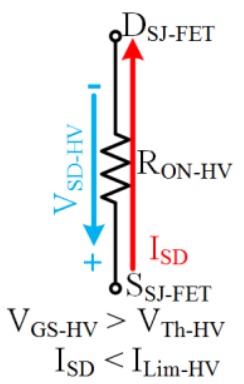

(b)

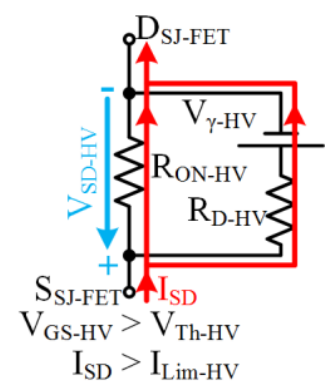

(c) standalone configuration when the switching frequency is in the order of hundreds of $\mathrm{kHz}$ and operating under hard-switching and high-forward current conditions [14]-[15]. Differently from the aforementioned papers, this work aims to model the third quadrant operation of the SJ-CC and to propose this configuration as a method to minimize the RR effect of the SJ-FET body-diode, enabling the use of these devices for SR [16].

This paper is organized as follows. The impact of the SJ-FET body-diode in SR is described in Section II together with a review of the techniques that have been proposed to alleviate this problem. The third quadrant operation of the SJ-CC is detailed in section III, including both the static and the dynamic analysis. Section IV is focused on the experimental results, including the third quadrant curves that validate the analytical model presented in Section II, and the RR evaluation that shows the improvement achieved by the SJ-CC. Finally, the conclusions are gathered in Section V.

\section{THIRD QUADRANT OPERATION OF A SJ-FET IN STANDALONE CONFIGURATION}

\section{A. Operating States of a SJ-FET in Reverse Conduction (Static Operation)}

Three different states can be identified when a SJ-FET in standalone configuration operates in the third quadrant. Fig. 2 shows the basic schematic for each state and the equivalent circuits are depicted in Fig. 3.

State $A$ [see Fig. 2(a) and Fig. 3(a)]. The SJ-FET is in offstate because the gate-to-source voltage of the device $\left(\mathrm{V}_{\mathrm{GS}} \mathrm{HV}\right)$ is lower than its threshold voltage $\left(\mathrm{V}_{\mathrm{Th}-\mathrm{HV}}\right)$. Then, the sourceto-drain current $\left(\mathrm{I}_{\mathrm{SD}}\right)$ flows entirely through the SJ-FET bodydiode $\left(\mathrm{D}_{\mathrm{HV}}\right)$ and the source-to-drain voltage $\left(\mathrm{V}_{\mathrm{SD}-\mathrm{HV}}\right)$ can be modeled as:

Fig. 3. Equivalent circuits of the SJ-FET in standalone configuration operating in third quadrant: (a) State A. (b) State B. (c) State C.

$$
V_{S D-H V}=I_{S D} \cdot R_{D-H V}+V_{\gamma-H V}
$$

where $\mathrm{V}_{\gamma-\mathrm{HV}}$ and $\mathrm{R}_{\mathrm{D}-\mathrm{HV}}$ are the knee voltage and the dynamic resistance of $\mathrm{D}_{\mathrm{HV}}$, respectively. It is important to note that $\mathrm{V}_{\gamma \text {-HV }}$ typically ranges between $0.6 \mathrm{~V}$ and $0.7 \mathrm{~V}$.

State $B$ [see Fig. 2(b) and Fig. 3(b)]: The SJ-FET is in onstate because $\mathrm{V}_{\mathrm{GS}-\mathrm{HV}}$ is higher than $\mathrm{V}_{\mathrm{Th}-\mathrm{HV}}$. Therefore, $\mathrm{I}_{\mathrm{SD}}$ flows completely through the channel of the SJ-FET. However, this is

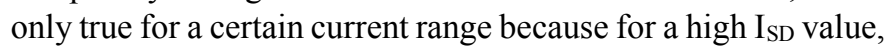
the voltage drop in $\mathrm{R}_{\mathrm{ON}-\mathrm{HV}}$ will overcome $\mathrm{V}_{\gamma-\mathrm{HV}}$ and, consequently, a current drift through $\mathrm{D}_{\mathrm{HV}}$ will appear. Hence, the next condition must be satisfied to operate in state B:

$$
I_{S D} \cdot R_{O N-H V}<V_{\gamma-H V}
$$

Therefore, the maximum current that the channel can conduct without activating $\mathrm{D}_{\mathrm{HV}}$ can be defined as:

$$
I_{L i m-H V}=\frac{V_{\gamma-H V}}{R_{O N-H V}} .
$$

In this state, $\mathrm{V}_{\mathrm{SD}-\mathrm{HV}}$ can be modeled as:

$$
V_{S D-H V}=I_{S D} \cdot R_{O N-H V} .
$$

State $C$ [see Fig. 2(c) and Fig. 3(c)]: The SJ-FET is in onstate because $\mathrm{V}_{\mathrm{GS}-\mathrm{HV}}$ is higher than $\mathrm{V}_{\mathrm{Th}-\mathrm{HV}}$. Differently from state $\mathrm{B}, \mathrm{D}_{\mathrm{HV}}$ is activated since $\mathrm{I}_{\mathrm{SD}}$ is higher than $\mathrm{I}_{\mathrm{Lim}-\mathrm{HV}}$. Hence, a part of the current flows through the SJ-FET channel while the other part flows through $\mathrm{D}_{\mathrm{HV}}$. In this state, $\mathrm{V}_{\mathrm{SD}-\mathrm{HV}}$ can be modeled as: 


$$
V_{S D-H V}=\frac{R_{O N-H V} \cdot R_{D-H V}}{R_{O N-H V}+R_{D-H V}}\left(I_{S D}+\frac{V_{\gamma-H V}}{R_{D-H V}}\right) .
$$

\section{B. Reverse Recovery of a SJ-FET (Dynamic Analysis)}

The RR of $\mathrm{D}_{\mathrm{HV}}$ appears when it is forced to stop conducting current and to block voltage [17]. Then, it will arise when the SJ-FET changes from states either A or C to off-state. Since it is important to understand when these transitions appear and their consequences, an example based on a synchronous boost converter will be given in this section. For the sake of simplicity, it is assumed that the inductor current $\left(\mathrm{I}_{\mathrm{L}}\right)$ is always positive. Hence, four stages can be identified.

In stage 1 [see Fig. 4(a)], the low-side SJ-FET $\left(\mathrm{Q}_{1}\right)$ is in onstate and the high-side SJ-FET $\left(\mathrm{Q}_{2}\right)$ is in off-state. Then, $\mathrm{I}_{\mathrm{L}}$ flows through the channel of $Q_{1}$. Note that since $I_{L}$ flows from the drain to the source, $\mathrm{Q}_{1}$ is operating in the first quadrant during this stage. On the other hand, during stage 3 [see Fig. 4(b)], $\mathrm{Q}_{1}$ is in off-state and $\mathrm{Q}_{2}$ is in on-state. Therefore, $\mathrm{I}_{\mathrm{L}}$ flows through the channel of $\mathrm{Q}_{2}$, which operates in the third quadrant (i.e., $\mathrm{I}_{\mathrm{L}}$ flows from the source to the drain). According to Section II.A, part of the current would flow through $\mathrm{D}_{\mathrm{HV}}$ if $\mathrm{I}_{\mathrm{L}}$ is higher than $\mathrm{I}_{\mathrm{Lim}-\mathrm{HV}}$ in stage 3 . However, as will be explained below, the $\mathrm{D}_{\mathrm{HV}}$ activation during this stage has minor impact on the RR effect.

In order to avoid shoot-through, dead-times between the turnoff of a transistor and the turn-on of the other transistor are mandatory. During dead-times, $\mathrm{I}_{\mathrm{L}}$ flows through the body-diode of $\mathrm{Q}_{2}$ [see Fig. 4(c)], which operates in state A. Stage 2 denotes the dead-time between the turn-off of $\mathrm{Q}_{1}$ and the turn-on of $\mathrm{Q}_{2}$ while Stage 4 considers the dead-time between the turn-off of $\mathrm{Q}_{2}$ and the turn-on of $\mathrm{Q}_{1}$. Stage 4 is particularly critical because when the dead-time ends (i.e., transition between stage 4 and stage 1), the body-diode of $\mathrm{Q}_{2}$ must stop conducting current and must start blocking voltage. Then, the RR caused by the accumulation of charge carriers arises because the body-diode needs to eliminate this charge before blocking any voltage. The charge elimination is done by generating an inverse current that flows through the channel of $\mathrm{Q}_{1}$ during its turn-on and, consequently, the $\mathrm{RR}$ of $\mathrm{Q}_{2}$ causes extra power losses in $\mathrm{Q}_{1}$ [17]. It is important to highlight that during dead-times, $\mathrm{I}_{\mathrm{L}}$ completely flows through the body-diode of $\mathrm{Q}_{2}$ whereas in the stage 3 , none or only a part of $I_{L}$ flows through it. Therefore, since the RR of $\mathrm{D}_{\mathrm{HV}}$ worsens with the current level, the possible activation of $D_{H V}$ during stage 3 has minor impact on the RR effect.

The RR of a MOSFET is typically evaluated in terms of RR time ( $\left.t_{R R}\right)$, $R R$ peak current ( $\left.I_{R R M}\right)$ and $R R$ charge $\left(Q_{R R}\right)$. The lower the parameters, the lower the RR impact. At this point, it is important to note that $\mathrm{Q}_{\mathrm{RR}}$ not only considers the actual $\mathrm{RR}$ charge of the SJ-FET body-diode (QRR-D-HV), but also the charge (Qoss-HV) stored in the output capacitance of the MOSFET (Coss-HV). Then, during its turn-on, $\mathrm{Q}_{1}$ conducts the inductor current (i.e., $\mathrm{I}_{\mathrm{L}}$ ), the current needed to charge the output capacitance of $\mathrm{Q}_{2}$, and the current needed to eliminate charge carriers that are accumulated in the body-diode of $\mathrm{Q}_{2}$. The

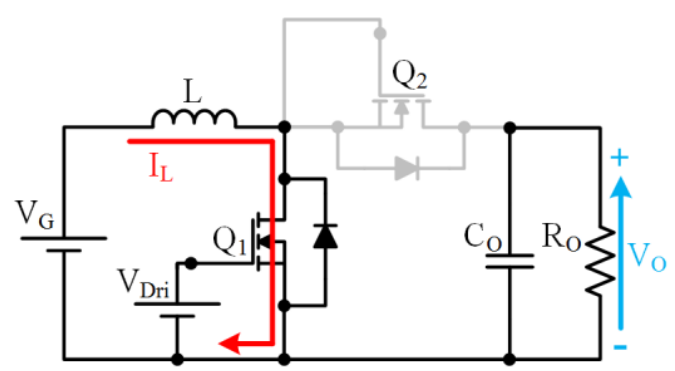

(a)

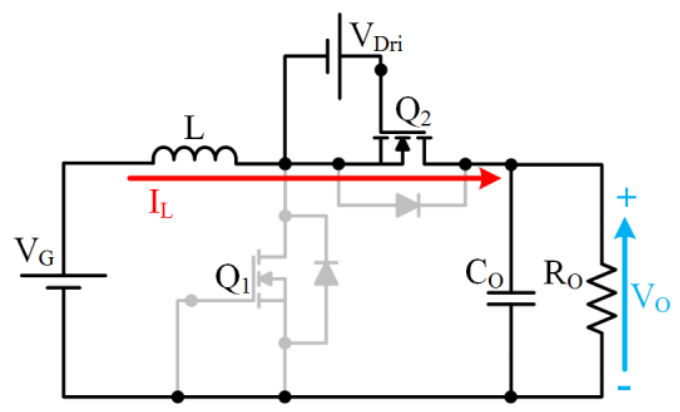

(b)

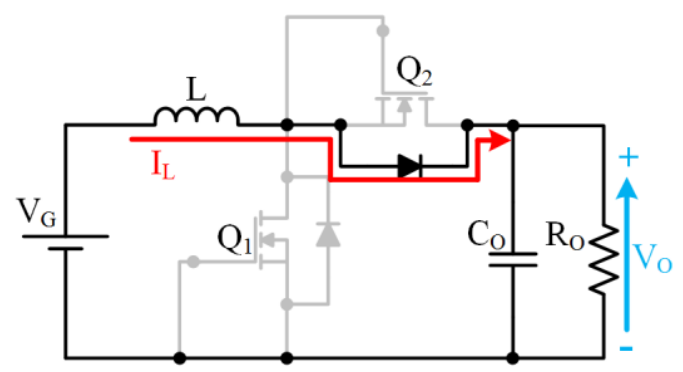

(c)

Fig. 4. Four stages of the synchronous boost converter assuming that $I_{L}$ is always positive: (a) Stage 1. (b) Stage 3. (c) Stages 2 and 4.

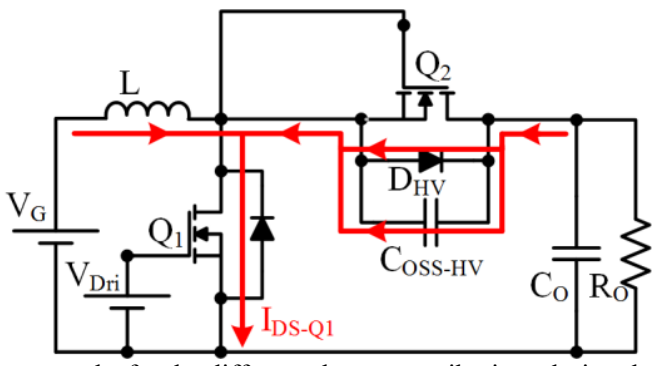

Fig. 5. Current paths for the different charge contributions during the RR of a SJ-FET in standalone configuration.

current paths for the different charge contributions when the RR takes place (i.e., during the transition between stage 4 and stage 1) are shown in Fig. 5. In the particular case of SJ-FETs, $Q_{R R}$ is dominated by QRR-D-HV, which rises with the temperature, the current level through $\mathrm{D}_{\mathrm{HV}}$ and the derivate of the drain current of $\mathrm{Q}_{1}$ during its turn-on $\left(d i_{D S-Q I} / d t\right)$. Fig. 6 exemplifies the main idealized waveforms involved in the RR process, highlighting $\mathrm{t}_{\mathrm{RR}}, \mathrm{I}_{\mathrm{RRM}}, \mathrm{Q}_{\mathrm{RR}}$, the drain-to-source voltage of $\mathrm{Q}_{1}\left(\mathrm{~V}_{\mathrm{DS}-\mathrm{Q} 1}\right)$ and the drain-to-source current of $\mathrm{Q}_{1}$ ( $\mathrm{I}_{\mathrm{DS}-\mathrm{Q} 1}$ ) during the transition between stage 4 and stage 1 (i.e., turn-on transition of $\mathrm{Q}_{1}$ ) [17].

In order to minimize the SJ-FET body-diode impact on SR, some techniques have been proposed by several authors in the past:

Dead-time minimization. Selecting the optimum dead-time 


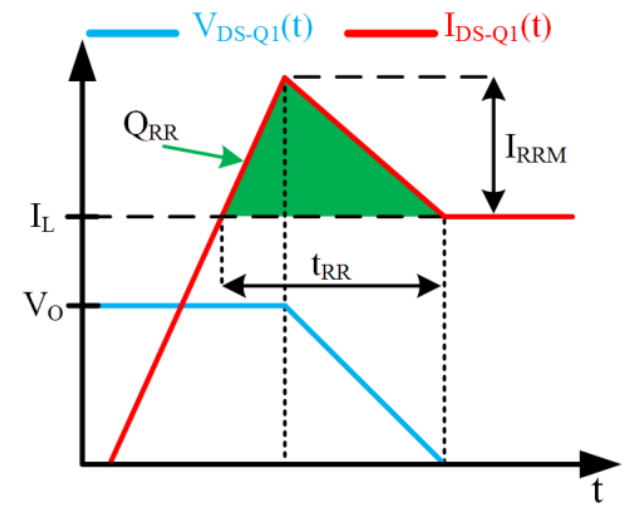

Fig. 6. Idealized voltage and current waveforms during the RR.

that completely avoids the activation of the SJ-FET body-diode is a direct method for minimizing $\mathrm{QRR}_{\mathrm{RR}}$ [18]-[20]. The difficulty is that the optimum dead-time depends on several factors, such as the operating conditions of the converter, and, consequently, auxiliary circuits are mandatory to ensure the minimum deadtimes for each situation, increasing the complexity. It is important to note than if the dead-time is shorter that the optimum one, a shoot-through that strongly deteriorates the efficiency takes place. On the other hand, if the dead-time is longer than the optimum one, the SJ-FET body-diode is activated and, as a consequence, $\mathrm{QRR}_{\mathrm{R}-\mathrm{D}-\mathrm{HV}}$ is not eliminated.

di $i_{D S-Q I} / d t$ minimization. This is another direct method to reduce the SJ-FET body-diode impact [18]. In this case, the approach is based on reducing the RR by minimizing $d i_{D S-Q I} / d t$ during the turn-on of $\mathrm{Q}_{1}$. Note that as was previously mentioned, the RR rises with $d i_{D S} / d t$. A straightforward method for reducing $d i_{D S} / d t$ is to increase the gate resistance of $\mathrm{Q}_{1}$. The drawback is that the switching losses caused by the coexistence of voltage and current at the channel of $\mathrm{Q}_{1}$ will rise because the device spends more time performing the switching transitions.

Sets of semiconductor devices acting as a single transistor. This technique includes all the approaches where several semiconductor devices are added in order to avoid the activation of the SJ-FET body-diode [18], [21]-[24]. Fig. 7(a) shows the easiest approach, where a Schottky diode $\left(\mathrm{D}_{\text {Schottky }}\right)$ is placed in antiparallel with the SJ-FET while the diode connected in series with the SJ-FET (D reverse current through the SJ-FET. The problem is that since the SJ-FET never operates in the third quadrant, this technique implies that SR is not performed. In addition, the conduction losses rise when the device operates in the first quadrant due to the $D_{\text {Blocking }}$ conduction. Several modifications have been proposed to solve the previous problems. For instance, Fig. 7(b) shows a configuration that adds a LV-FET to block the third quadrant operation of the SJ-FET only when it is desired [21], [23]. However, the approach increases the complexity not only because of the higher number of elements, but also because a delay must be added in the turn-off gate signal of the SJ-FET with respect to the LV-FET one.

SJ-FET with fast body-diode. SJ-FETs focused on improving the third quadrant operation can be found in the market. Although Schottky diodes co-integration was initially proposed

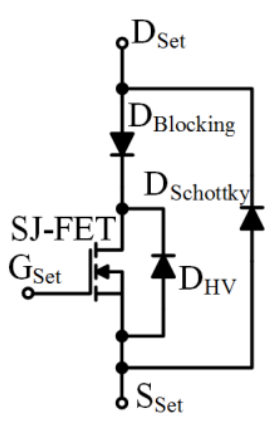

(a)

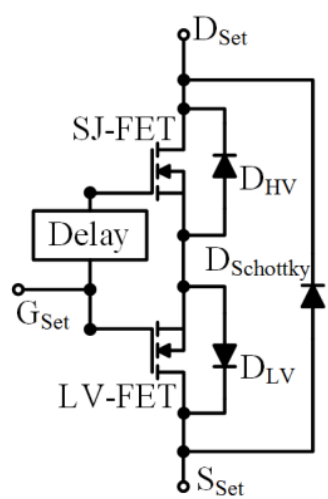

(b)
Fig. 7. Two approaches based on using a set of semiconductor devices acting as a single transistor: (a) SJ-FET with antiparallel Schottky diode. (b) SJ-FET in combination with a LV-FET, a Schottky diode and a delay.

[25], current SJ-FETs with enhanced RR are mainly based on irradiation process [26]-[28]. Device irradiation normally requires special facilities, thus adding cost and jeopardizing other electrical parameters such as $\mathrm{V}_{\mathrm{Th}-\mathrm{HV}}, \mathrm{R}_{\mathrm{ON}-\mathrm{HV}}$ or leakage current.

Snubbers. This technique includes the approaches based on the use of an auxiliary circuit to suppress the impact of the SJ-FET body-diode on $\mathrm{Q}_{1}$ [29]-[31]. In general, this kind of approaches increases the number of elements, which is translated into higher cost and more parasites.

Soft-switching. The use of resonant converters mitigates the impact of the SJ-FET body-diode [32]-[34]. However, they add the problems related to the resonant conversion itself, such as the losses caused by the higher RMS currents.

\section{THIRD QUADRANT OPERATION OF A SJ-CC}

\section{A. Operating States of a SJ-CC in Reverse Conduction (Static} Analysis)

Five different states can be identified during the third quadrant operation of a SJ-CC. The operating state depends on the gate-to-source voltage of the LV-FET ( $\left.\mathrm{V}_{\mathrm{GS}-\mathrm{LV}}\right)$, the on-state resistance of the LV-FET (RON-LV), the threshold voltage of the LV-FET $\left(\mathrm{V}_{\mathrm{Th}-\mathrm{LV}}\right)$, the knee-voltage $\left(\mathrm{V}_{\gamma \text {-LV }}\right)$ and the dynamic resistance $\left(\mathrm{R}_{\mathrm{D}-\mathrm{LV}}\right)$ of the LV-FET body-diode $\left(\mathrm{D}_{\mathrm{LV}}\right)$, the on-

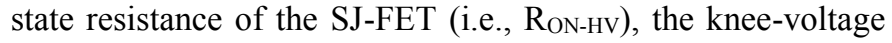
(i.e., $\left.\mathrm{V}_{\gamma \text {-HV }}\right)$ and the dynamic resistance $\left(\mathrm{R}_{\mathrm{D}-\mathrm{HV}}\right)$ of the SJ-FET body-diode (i.e., $\mathrm{D}_{\mathrm{HV}}$ ), and the source-to-drain current (i.e., ISD). Fig. 8 shows the basic schematics for each state and the equivalent circuits are depicted in Fig. 9.

State 1 [see Fig. 8(a) and Fig. 9(a)]. The LV-FET is in offstate because $\mathrm{V}_{\mathrm{GS}-\mathrm{LV}}$ is lower than $\mathrm{V}_{\text {Th-LV}}$. Then, ISD flows completely through $\mathrm{D}_{\mathrm{LV}}$ and, therefore, the source-to-drain voltage of the LV-FET ( $\left.\mathrm{V}_{\mathrm{SD}-\mathrm{LV}}\right)$ can be modeled as:

$$
V_{S D-L V}=V_{\gamma-L V}+I_{S D} \cdot R_{D-L V} \cdot
$$

Therefore, $\mathrm{V}_{\mathrm{GS}-\mathrm{HV}}$ is equal to:

$$
V_{G S-H V}=V_{A}+v_{S D-L V}
$$




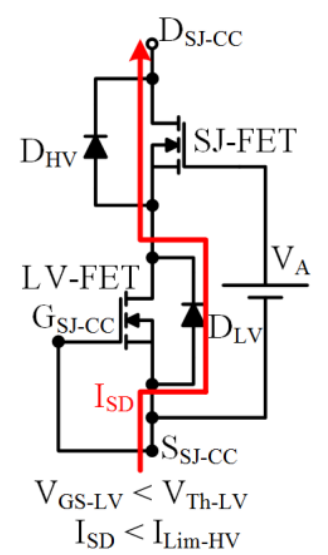

(a)

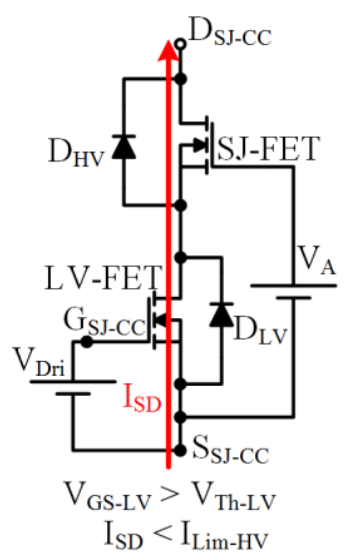

(c)

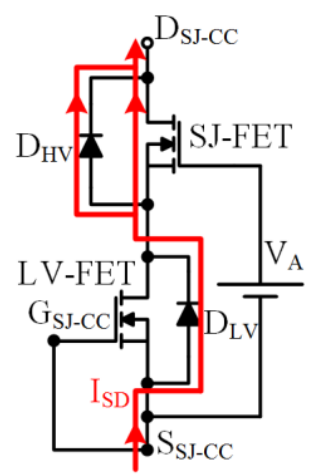

$\mathrm{V}_{\mathrm{GS}-\mathrm{LV}}<\mathrm{V}_{\mathrm{Th}-\mathrm{LV}}$

$\mathrm{I}_{\mathrm{SD}}>\mathrm{I}_{\text {Lim-HV }}$

(b)

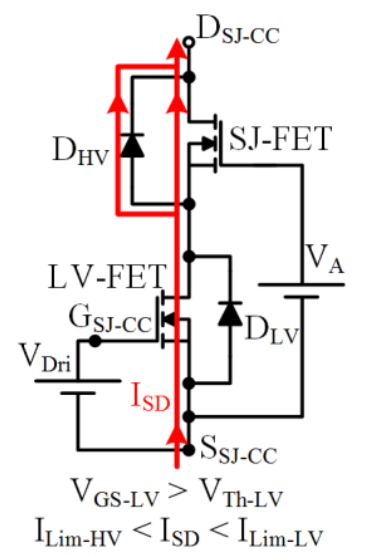

(d)

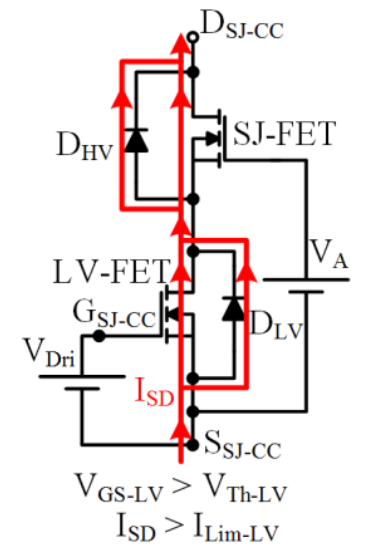

(e)
Fig. 8. Basic schematics of the SJ-CC operating in third quadrant: (a) State 1. (b) State 2. (c) State 3. (d) State 4. (e) State 5.

$V_{A}$ should be selected high enough to ensure that $V_{G S-H V}$ is higher than $\mathrm{V}_{\mathrm{Th}-\mathrm{HV}}$ under these conditions. In this sense, $\mathrm{V}_{\mathrm{A}}$ higher than $10 \mathrm{~V}$ is enough to guarantee the desired operation. A suitable approach consists in obtaining $\mathrm{V}_{\mathrm{A}}$ from the voltage supply of the LV-FET gate driver (i.e., $\mathrm{V}_{\mathrm{A}}=\mathrm{V}_{\text {Dri }}$ ). In any case, since $\mathrm{V}_{\mathrm{GS}-\mathrm{HV}}$ is higher than $\mathrm{V}_{\mathrm{Th}-\mathrm{HV}}$, the $\mathrm{SJ}$-FET is in on-state and, therefore, the current flows through the channel of the SJFET. As in the case of the standalone configuration, $\mathrm{D}_{\mathrm{HV}}$ can be activated for high $\mathrm{I}_{\mathrm{SD}}$ values (i.e., $\mathrm{I}_{\mathrm{SD}}>\mathrm{I}_{\mathrm{Lim}-\mathrm{HV}}$ ). However, this state considers that $\mathrm{I}_{\mathrm{SD}}$ is lower than $\mathrm{I}_{\mathrm{Lim}-\mathrm{HV}}$ and, consequently, $\mathrm{D}_{\mathrm{HV}}$ is not activated. Then, equation (4) can be used to model $\mathrm{V}_{\mathrm{SD}-\mathrm{HV}}$.

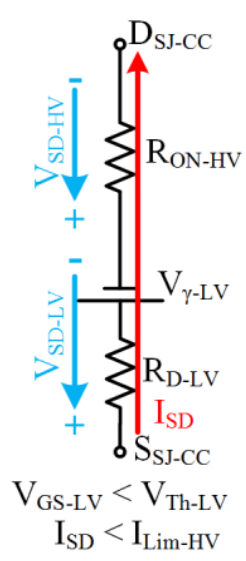

(a)

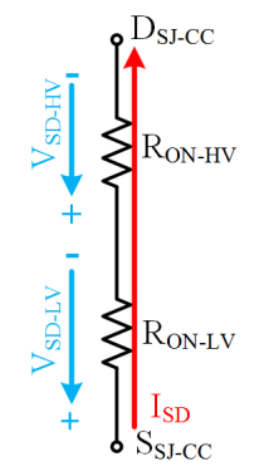

$\mathrm{V}_{\mathrm{GS}-\mathrm{LV}}>\mathrm{V}_{\mathrm{Th}-\mathrm{LV}}$

$\mathrm{I}_{\mathrm{SD}}<\mathrm{I}_{\text {Lim-HV }}$

(c)

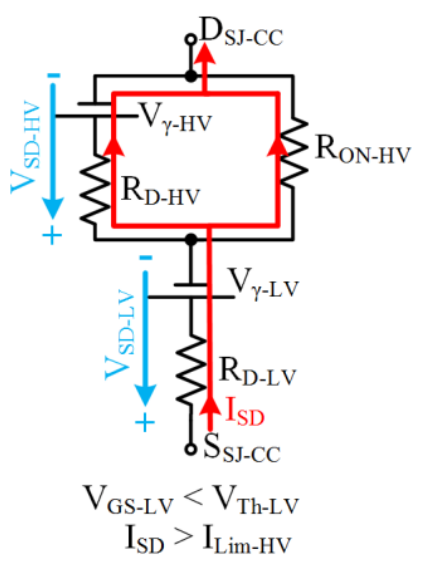

(b)

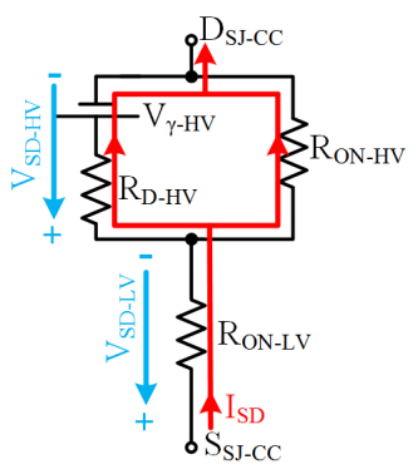

$\mathrm{V}_{\mathrm{GS}-\mathrm{LV}}>\mathrm{V}_{\text {Th-LV }}$

$\mathrm{I}_{\text {Lim-HV }}<\mathrm{I}_{\mathrm{SD}}<\mathrm{I}_{\text {Lim-LV }}$

(d)

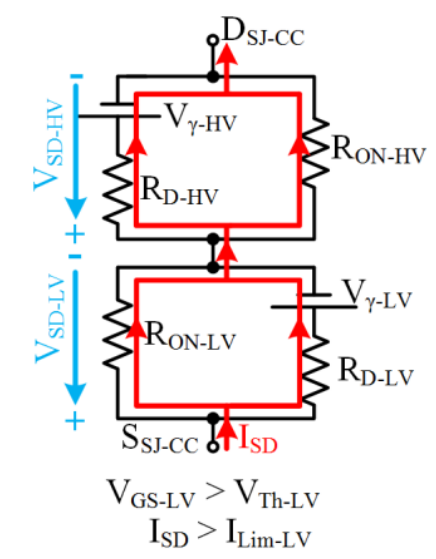

(e)

Fig. 9. Equivalent circuits of the SJ-CC operating in third quadrant: (a) State 1. (b) State 2. (c) State 3. (d) State 4. (e) State 5.

State 2 [see Fig. 8(b) and Fig. 9(b)]. As in the previous state, the LV-FET is in off-state because $\mathrm{V}_{\text {GS-LV }}$ is lower than $\mathrm{V}_{\text {Th-LV }}$ and, consequently, the SJ-FET is in on-state since $\mathrm{V}_{\mathrm{GS}-\mathrm{HV}}$ is almost equal to $\mathrm{V}_{\mathrm{A}}$. Then, the current flows through $\mathrm{D}_{\mathrm{LV}}$ and equation (6) is valid to model the voltage drop at the LV-FET. The difference with respect to state 1 is that $\mathrm{I}_{\mathrm{SD}}$ is higher than $\mathrm{I}_{\text {Lim-HV}}$, which causes a current drift through $\mathrm{D}_{\mathrm{HV}}$. Under these conditions, the voltage drop at the SJ-FET can be modeled using equation (5).

State 3 [see Fig. 8(c) and Fig. 9(c)]. The LV-FET is in onstate because $\mathrm{V}_{\mathrm{GS}-\mathrm{LV}}$ is higher than $\mathrm{V}_{\mathrm{Th}-\mathrm{LV}}$. Then, $\mathrm{I}_{\mathrm{SD}}$ completely flows through the channel of the LV-FET and $\mathrm{V}_{\text {SD-LV }}$ can be 
modeled as:

$$
V_{S D-L V}=I_{S D} \cdot R_{O N-L V}
$$

As in the previous states, $\mathrm{V}_{\mathrm{GS}-\mathrm{HV}}$ is almost equal to $\mathrm{V}_{\mathrm{A}}$ and, therefore, the SJ-FET is in on-sate. State 3 considers that $\mathrm{ISD}_{\mathrm{SD}}$ is

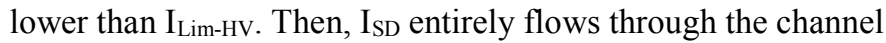
of the SJ-FET and $\mathrm{D}_{\mathrm{HV}}$ is not activated. Equation (4) is valid to model $\mathrm{V}_{\mathrm{SD}-\mathrm{HV}}$ during this state.

State 4 [see Fig. 8(d) and Fig. 9(d)]. As in the previous state, the LV-FET is in on-state because $\mathrm{V}_{\mathrm{GS}-\mathrm{LV}}$ is higher than $\mathrm{V}_{\text {Th-LV }}$ and, therefore, the $\mathrm{SJ}$-FET is in on-state since $\mathrm{V}_{\mathrm{GS}-\mathrm{HV}}$ is almost equal to $\mathrm{V}_{\mathrm{A}}$. Then, the current flows through the channel of the LV-FET and equation (8) is valid to model $\mathrm{V}_{\text {SD-LV. The }}$ difference with respect to state 3 is that $\mathrm{I}_{\mathrm{SD}}$ is higher than $\mathrm{I}_{\mathrm{Lim}-\mathrm{HV}}$, which causes a current drift through $\mathrm{D}_{\mathrm{HV}}$. Under these conditions, $\mathrm{V}_{\mathrm{SD}-\mathrm{HV}}$ can be modeled according to equation (5).

State 5 [see Fig. 8(e) and Fig. 9(e)]. From a theoretical point of view, an ISD value high enough could impose a current drift through $\mathrm{D}_{\mathrm{LV}}$ and a fifth state would have to be taken into account when $\mathrm{V}_{\mathrm{GS}-\mathrm{LV}}$ is higher than $\mathrm{V}_{\text {Th-LV. However, }}$ considering the low $R_{\mathrm{ON}-\mathrm{LV}}$ value (tens of $\mathrm{m} \Omega$ ), the $\mathrm{I}_{\mathrm{SD}}$ value required for reaching this state (above $60 \mathrm{~A}$ considering current LV-FET technology) makes no sense for the current rating of the SJ-FETs. In any case, this state will be studied next in order to provide a consistent model. Since $\mathrm{D}_{\mathrm{LV}}$ is activated during this state, the following condition must be satisfied:

$$
I_{S D} \cdot R_{O N-L V}>V_{\gamma-L V}
$$

Then, $\mathrm{D}_{\mathrm{LV}}$ is activated once the following current limit is overcome:

$$
I_{L i m-L V}=\frac{V_{\gamma-L V}}{R_{O N-L V}}
$$

Taking into account all the previous statements, equation (5) is valid to model $\mathrm{V}_{\mathrm{SD}-\mathrm{HV}}$ and $\mathrm{V}_{\mathrm{SD}-\mathrm{LV}}$ can be modeled as:

$$
V_{S D-L V}=\frac{R_{O N-L V} \cdot R_{D-L V}}{R_{O N-L V}+R_{D-L V}}\left(I_{S D}+\frac{V_{\gamma-L V}}{R_{D-L V}}\right)
$$

\section{B. Reverse Recovery of a SJ-CC (Dynamic Analysis)}

The RR effect of a SJ-CC takes place when the whole transistor is forced to block voltage after operating in the third quadrant. Continuing with the example of the synchronous boost converter detailed in Section II.B, the RR effect appears after the dead-time between the turn-off of the SJ-CC and the turn-on of the low-side transistor (i.e., transition between the stage 4 and the stage 1 of the synchronous boost converter). Taking into account that $\mathrm{V}_{\mathrm{GS}-\mathrm{LV}}$ is $0 \mathrm{~V}$ during dead-times, the RR effect implies that SJ-CC moves from states 1 or 2 to offstate.

As in the standalone configuration, $\mathrm{t}_{\mathrm{RR}}, \mathrm{I}_{\mathrm{RRM}}$ and $\mathrm{Q}_{\mathrm{RR}}$ can be used to evaluate the RR. As Fig. 10 shows, there are four sources of $\mathrm{Q}_{\mathrm{RR}}$ in the case of the $\mathrm{SJ}$-CC. It can be seen that $\mathrm{Q}_{\mathrm{RR}}$ considers not only $\mathrm{Q}_{\mathrm{RR}-\mathrm{D}-\mathrm{HV}}$ and Qoss-HV, but also the RR charge of the LV-FET body-diode (QRR-D-LV) and the charge (Qoss-LV) stored in the output capacitance of the LV-FET (Coss-LV). It is important to note that the major contribution theoretically

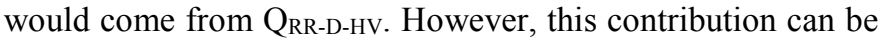
eliminated or mitigated if the SJ-CC is properly designed according to the current level that is going to drive (i.e., using a SJ-FET with $\mathrm{R}_{\mathrm{ON}-\mathrm{HV}}$ low enough to ensure that $\mathrm{V}_{\mathrm{SD}-\mathrm{HV}}$ never reaches $\mathrm{V}_{\gamma-\mathrm{HV}}$ for the considered $\mathrm{I}_{\mathrm{SD}}$ ). If the previous condition is satisfied, Qoss-Hv would become the most relevant source of QRR. Regarding the LV-FET contributions, both QRR-D-LV and Qoss-Lv have minor impact in comparison to the two first sources of QRR.

Differently from the standalone configuration, the SJ-CC avoids or mitigates the impact of $\mathrm{D}_{\mathrm{HV}}$ on the RR (i.e., QRR-D-HV). Basically, if the SJ-CC operates in state 1 during the deadtimes, $\mathrm{QRR}_{\mathrm{R}-\mathrm{D}-\mathrm{HV}}$ is completely removed by avoiding the activation of $\mathrm{D}_{\mathrm{Hv}}$. Moreover, if the SJ-CC operates in state 2, QRR-D-HV will be lower than in the case of the standalone configuration because only a part of the current flows through $\mathrm{D}_{\mathrm{HV}}$. Remember that in the case of the standalone configuration, $\mathrm{D}_{\mathrm{HV}}$ conducts all the current during the dead-times (check state A in Section II.A). This is the key point that explains why the SJ-CC achieves a better third quadrant behavior than the standalone counterpart. It is important to note that although the aforementioned reasoning seems obvious, it has not been previously reported in the literature.

Fig. 11 shows the theoretical current [following equations (1) to (11)] that flows during the dead-times through the channel of a SJ-FET in standalone configuration $\left(\mathrm{I}_{\mathrm{Ch}-\mathrm{HV}-\mathrm{St}}\right)$, through the channel of the same SJ-FET in CC ( $\left.\mathrm{I}_{\mathrm{Ch}-\mathrm{HV}-\mathrm{CC}}\right)$, through $\mathrm{D}_{\mathrm{HV}}$ in standalone configuration ( $\left.\mathrm{I}_{\mathrm{D}-\mathrm{HV}-\mathrm{St}}\right)$ and through $\mathrm{D}_{\mathrm{HV}}$ in $\mathrm{CC}\left(\mathrm{I}_{\mathrm{D}-}\right.$ HV-CC) versus $\mathrm{I}_{\mathrm{SD}}$. As previously explained, all the current flows through $\mathrm{D}_{\mathrm{HV}}$ regardless the current level in the standalone configuration. In the case of the SJ-CC, the current completely flows through the channel of the SJ-FET when ISD is lower than $\mathrm{I}_{\mathrm{Lim}-\mathrm{HV}}$. For higher current levels, $\mathrm{D}_{\mathrm{HV}}$ is activated and the current shared depends on $\mathrm{V}_{\gamma-\mathrm{HV}}, \mathrm{R}_{\mathrm{D}-\mathrm{HV}}$ and $\mathrm{R}_{\mathrm{ON}-\mathrm{HV}}$, and can be determined by using (4) and (5). Typically, $\mathrm{R}_{\mathrm{D}-\mathrm{HV}}$ is lower than $\mathrm{R}_{\mathrm{ON}-\mathrm{HV}}$ and, consequently, the slope of $\mathrm{I}_{\mathrm{D}-\mathrm{HV}-\mathrm{CC}}$ is higher than that of $\mathrm{I}_{\mathrm{Ch}-\mathrm{HV}-\mathrm{CC}}$ once $\mathrm{I}_{\mathrm{Lim}-\mathrm{HV}}$ is overcome.

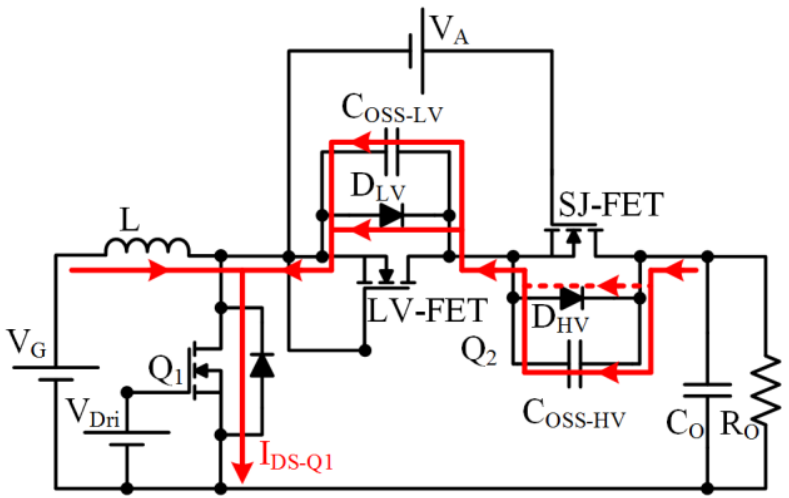

Fig. 10. Current paths for the different charge contributions during the RR of a SJ-CC. The dashed line highlights the possibility of eliminating $\mathrm{QRR}_{\mathrm{R}-\mathrm{D}-\mathrm{HV}}$ when the $\mathrm{SJ}-\mathrm{CC}$ is properly designed. 


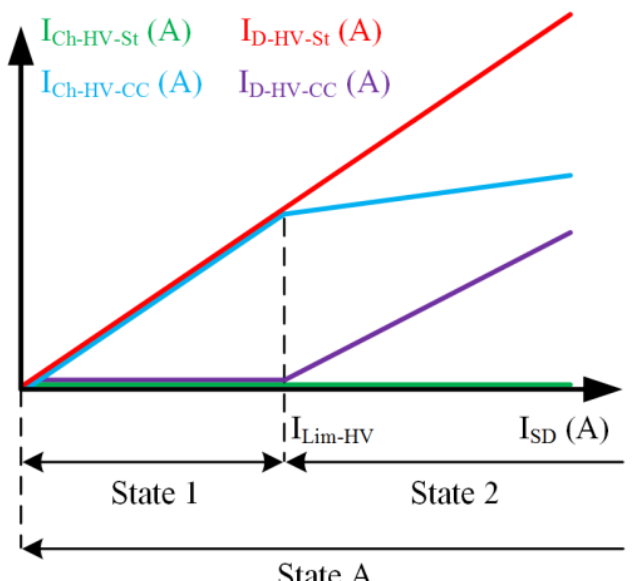

State A

Fig. 11. Theoretical current that flows during the dead-times through the channel of a SJ-FET in standalone configuration $\left(\mathrm{I}_{\mathrm{Ch}-\mathrm{HV}-\mathrm{St}}\right)$, through the channel of the same SJ-FET in CC ( $\left.\mathrm{I}_{\mathrm{Ch}-\mathrm{HV}-\mathrm{CC}}\right)$, through $\mathrm{D}_{\mathrm{HV}}$ in standalone configuration ( $\left.\mathrm{I}_{\mathrm{D}-\mathrm{HV}-\mathrm{St}}\right)$ and through $\mathrm{D}_{\mathrm{HV}}$ in the $\mathrm{CC}\left(\mathrm{I}_{\mathrm{D}-\mathrm{HV}-\mathrm{CC}}\right)$ versus $\mathrm{I}_{\mathrm{SD}}$.

\section{EXPERIMENTAL RESULTS}

Although more than 40 SJ-CCs were implemented combining different SJ-FETs and LV-FETs, the most representative cases will be considered in this paper. As Fig. 1(b) shows, the implementations were made with discrete devices in a plug-in board. It is important to note that SJ-FETs optimized for hard-switching from the major manufactures were used for these implementations. The main electrical parameters of the SJ-FETs and the LV-FETs that will be mentioned along the rest of the paper are summarized in Table I and Table II, respectively. It is important to note that each particular SJ-CC design is identified with two numbers along the rest of the paper. The first number identifies the SJ-FET whereas the second number identifies the LV-FET. For instance, SJ-CC 3-1 implies that the SJ-CC is made up of the SJ-FET 3 and the LV-FET 1.

\section{A. Reverse Conduction Curves of the SJ-CC (Static Analysis)}

The SJ-CC reverse conduction model presented in Section III is validated by measuring experimentally the static third

TABLE I. MAIN Electrical PaRAMETERS OF THE SJ-FETS USED IN THE DIFFERENT SJ-CC PROTOTYPES

\begin{tabular}{|l|c|c|c|c|c|}
\cline { 2 - 6 } \multicolumn{1}{c|}{} & $\begin{array}{c}\mathbf{B V}_{\text {DSS }} \\
(\mathbf{V})\end{array}$ & $\begin{array}{c}\mathbf{R}_{\text {ON-HV }} \\
(\mathbf{m} \boldsymbol{\Omega})\end{array}$ & $\begin{array}{c}\mathbf{Q}_{\text {GD }} \\
(\mathbf{n C})\end{array}$ & $\begin{array}{c}\mathbf{Q}_{\mathrm{G}} \\
(\mathbf{n C})\end{array}$ & $\begin{array}{c}\mathbf{Q}_{\text {oss }}{ }^{* 1} \\
(\mathbf{n C})\end{array}$ \\
\hline SJ-FET 1 & 600 & 178 & 27 & 51 & 124 \\
\hline SJ-FET 2 & 600 & 136 & 22 & 48 & 153 \\
\hline SJ-FET 3 & 650 & 123 & 11 & 35 & 239 \\
\hline
\end{tabular}

TABLE II. MAIN Electrical PARAMETERS OF THE LV-FETs USED IN THE DIFFERENT SJ-CC PROTOTYPES

\begin{tabular}{|l|c|c|c|c|c|}
\cline { 2 - 6 } \multicolumn{1}{c|}{} & $\begin{array}{c}\mathbf{B V}_{\text {DSS }} \\
(\mathbf{V})\end{array}$ & $\begin{array}{c}\mathbf{R}_{\text {ON-LV }} \\
(\mathbf{m} \mathbf{\Omega})\end{array}$ & $\begin{array}{c}\mathbf{Q}_{\mathrm{GD}} \\
(\mathbf{n C})\end{array}$ & $\begin{array}{c}\mathbf{Q}_{\mathrm{G}} \\
(\mathbf{n C})\end{array}$ & $\begin{array}{c}\mathbf{Q}_{\text {oss }}{ }^{* 1} \\
(\mathbf{n C})\end{array}$ \\
\hline LV-FET 1 & 30 & 8.1 & $1.7^{*_{1}}$ & $5.5^{* 1}$ & $11^{*_{1}}$ \\
\hline LV-FET 2 & 12 & 7.5 & $0.76^{* 2}$ & $3.1^{* 2}$ & $5.7^{*_{2}}$ \\
\hline LV-FET 3 & 30 & 4.4 & $1.4^{* 1}$ & $5.2^{* 1}$ & $7.2^{* 1}$ \\
\hline
\end{tabular}

quadrant curves of the SJ-CC prototypes. Fig. 12 shows the analytical [following equations (1) to (11)] and the experimental static third quadrant curves of different SJ-CC designs, identifying the operating states with a circle. It is important to note that state 5 cannot be shown because, as previously mentioned, $\mathrm{I}_{\mathrm{Lim}-\mathrm{LV}}$ cannot be reached due to the current ratings of the SJ-FETs. The designs used in Fig. 12(a) have the same SJ-FET and different LV-FETs. It can be seen that changing the LV-FET has minor impact on the static reverse conduction behavior of the SJ-CC. Note that this does not imply that both designs provide the same dynamic behavior. This point will be studied in Section IV.B. The designs used in Fig. 12(b) have the same LV-FET and different SJ-FETs. In this case, it can be concluded that changing the SJ-FET has major impact on the static reverse conduction behavior of the SJ-CC. It is important to note that static reverse conduction refers to the third quadrant operation of transistors without performing any switching. As Fig. 12(b) shows, $\mathrm{V}_{\gamma-\mathrm{HV}}$ is similar in both SJ-

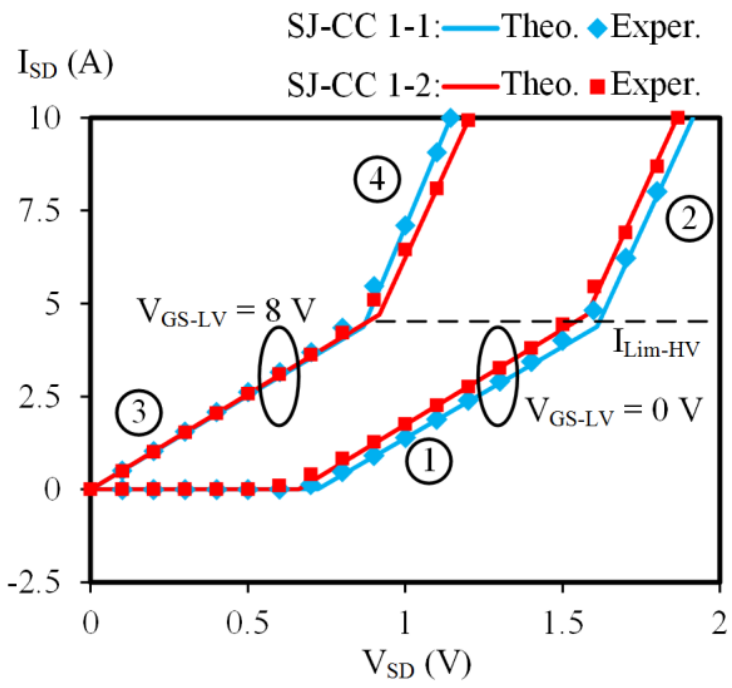

(a)

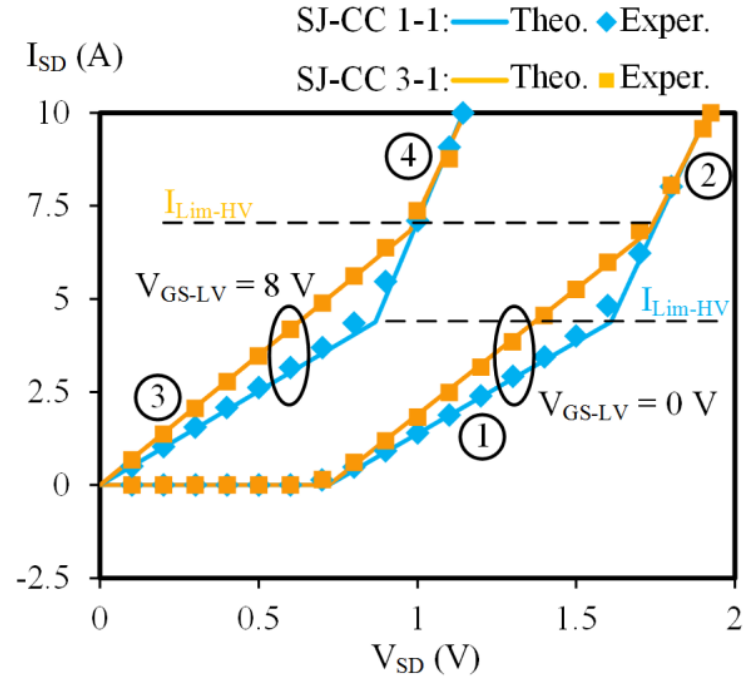

(b)

Fig. 12. Analytical (solid lines) and experimental (markers) static third quadrant curves of different SJ-CC designs highlighting the operating states: (a) Two SJ-CC designs with the same SJ-FET and different LV-FETs. (b) Two SJ-CC designs with the same LV-FET and different SJ-FETs. 
FETs and, therefore, the SJ-FET voltage drop needed to activate $\mathrm{D}_{\mathrm{HV}}$ is also similar. For the same $\mathrm{I}_{\mathrm{SD}}$ level, $\mathrm{V}_{\mathrm{SD}-\mathrm{HV}}$ is higher in the case of the SJ-CC 1-1 because R $\mathrm{ON}_{\mathrm{HV}}$ is higher, which is translated into a lower I Iim-HV value. As a result, the SJ-CC 3-1 can address higher current levels without activating $\mathrm{D}_{\mathrm{HV}}$.

Finally, Fig. 13 shows the static reverse conduction curves of the same SJ-FET in standalone configuration and in $\mathrm{CC}$ with the LV-FET 1. Note that $\mathrm{I}_{\text {Lim-HV }}$ is the same in both configurations.

\section{B. Reverse Recovery of a SJ-CC (Dynamic Analysis)}

In order to characterize the RR of the SJ-FETs, both in cascode and in standalone configuration, a boost converter is used replacing the power rectifier by a transistor with a short circuit between its gate and its source (see Fig. 14). Except for the Device Under Test (DUT), which can be a SJ-FET in standalone configuration or a SJ-CC, all the components of the boost converter are fixed, including the SJ-FET in standalone configuration that is used as low-side transistor. The switching frequency is $100 \mathrm{kHz}$ and the inductor was designed to ensure

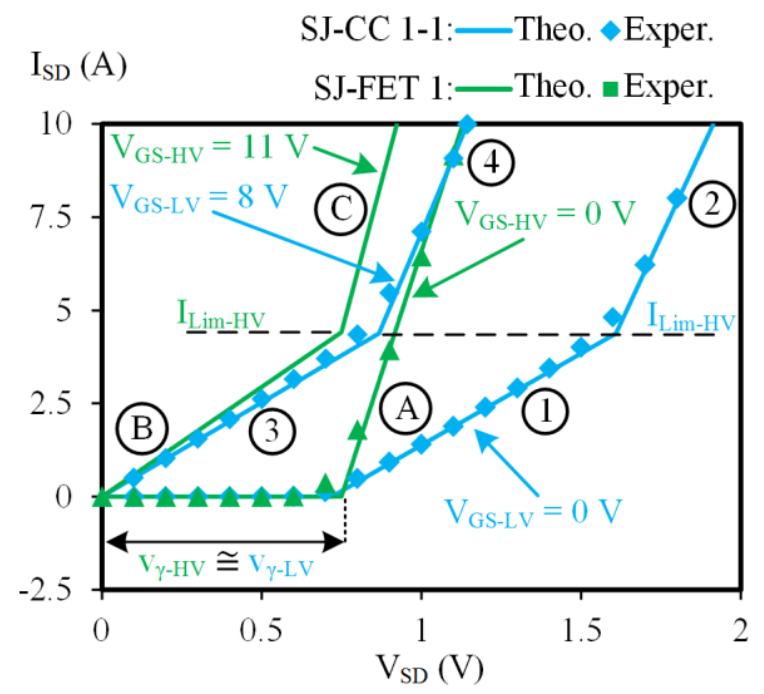

Fig. 13. Analytical (solid lines) and experimental (markers) static third quadrant curves of the SJ-FET 1 in standalone configuration and in $\mathrm{CC}$ with the LV-FET 1 highlighting the different operating states.

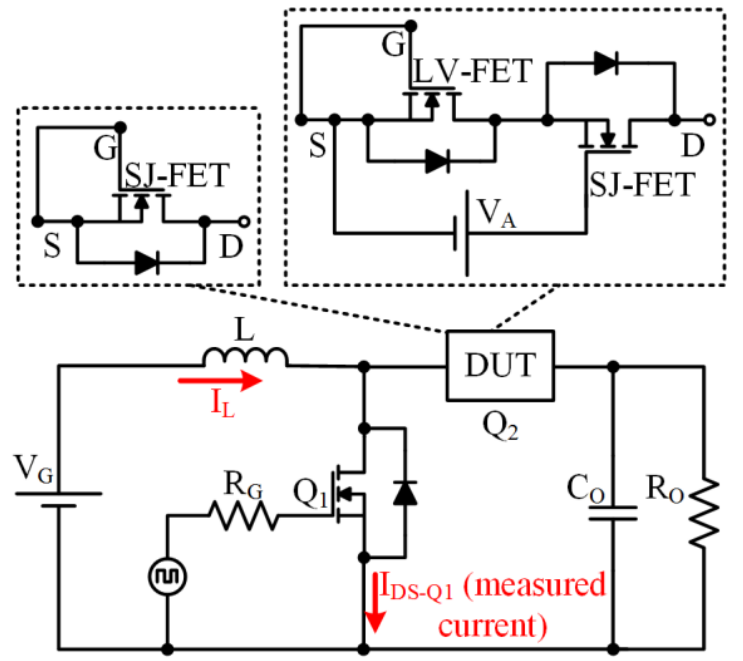

Fig. 14. Schematic of the boost converter used to characterize the RR of the DUT (either SJ-FETs in standalone configuration or SJ-CCs). a negligible current ripple.

The current that flows through the low-side transistor (i.e., $\left.i_{D S-Q 1}\right)$ is measured during the turn-on in order to evaluate $t_{R R}$, $\mathrm{I}_{\mathrm{RRM}}$ and $\mathrm{Q}_{\mathrm{RR}}$. $d i_{D S-Q 1} / d t$ is controlled by the gate resistance of the low-side transistor and it is fixed to $130 \mathrm{~A} / \mu$ s for the RR tests. Note that the input and output voltages are $12.5 \mathrm{~V}$ and 50 $\mathrm{V}$, respectively. Therefore, the DUT blocks $50 \mathrm{~V}$ during the offstate. Below, it is explained why this value is high enough to characterize the RR of the DUTs even when the used SJ-FETs are able to block voltages up to $600 \mathrm{~V}$. In order to analyze the RR of the DUTs under different conditions, the tests are carried out at three $\mathrm{I}_{\mathrm{L}}$ values: $1.2 \mathrm{~A}, 2.4 \mathrm{~A}$ and $6 \mathrm{~A}$. The current waveform are captured in less than one second in order to mitigate the temperature impact. An example is given in Fig. 15 , which shows the measured current when a SJ-FET is used either in $\mathrm{CC}$ or in standalone configuration. Note that the figure changes the vertical axis subtracting $\mathrm{I}_{\mathrm{L}}$ in order to identify the $\mathrm{RR}$ in an easily way. This first experimental result shows that the SJ-CC clearly improves the third quadrant dynamic behavior with respect to the standalone counterpart. It can be seen that $t_{R R}, I_{R R M}$ and $Q_{R R}$ are lower in the case of the SJ-CC.

In Section IV.C the comparison between the RR of SJ-CCs and SJ-FETs in standalone configuration is analyzed in detail at different operating conditions. In this section, only the RR of the SJ-CC is characterized, omitting any comparison with other power transistors.

Fig. 16 shows the current waveforms for three SJ-CC designs that have the same LV-FET and different SJ-FETs. According to (3) and as Fig. 12 shows, $\mathrm{I}_{\mathrm{Lim}-\mathrm{HV}}$ is around $4 \mathrm{~A}$ and $6 \mathrm{~A}$ for the SJ-CC 1-1 and the SJ-CC 3-1, respectively. Note that $\mathrm{I}_{\mathrm{Lim}-}$ $\mathrm{HV}$ is around 5.1 A in the case of the SJ-CC 2-1. Therefore, the three SJ-CCs operate in state 1 and the activation of $\mathrm{D}_{\mathrm{HV}}$ is avoided when the current level is $1.2 \mathrm{~A}$ or $2.4 \mathrm{~A}$. As a result, there is no appreciable deterioration of the $R R$ when $I_{L}$ rises from $1.2 \mathrm{~A}$ to $2.4 \mathrm{~A}$. When the current is $6 \mathrm{~A}$, the $\mathrm{SJ}-\mathrm{CC} 1-1$ and the SJ-CC 2-1 operate in state 2, whereas the SJ-CC 3-1 operates close to the limit between states 1 and 2 . Therefore, the deterioration of the RR in the case of SJ-CC 1-1 and SJ-CC 21 at this current level is caused by the activation of $\mathrm{D}_{\mathrm{HV}}$.

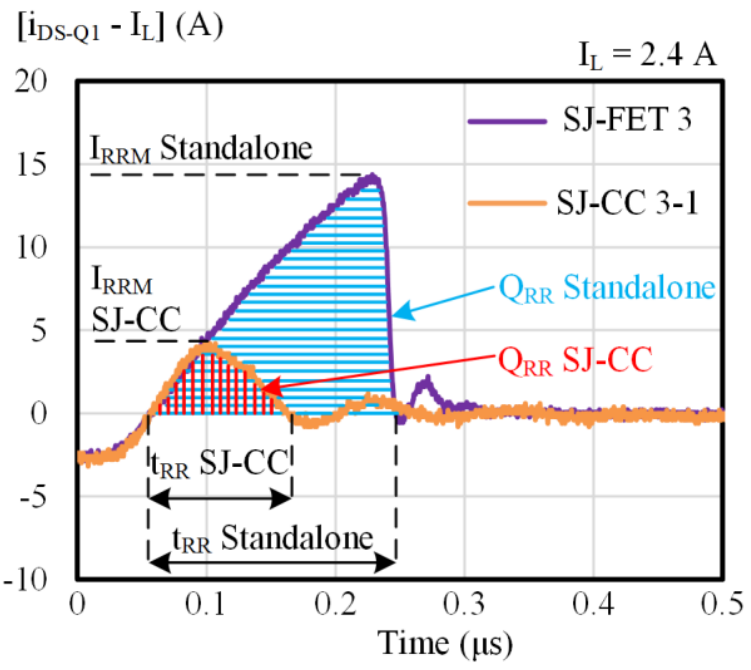

Fig. 15. Experimental comparison between the RR of the SJ-FET 3 in CC with the LV-FET 1 and in standalone configuration when $\mathrm{I}_{\mathrm{L}}$ is equal to $2.4 \mathrm{~A}$. 


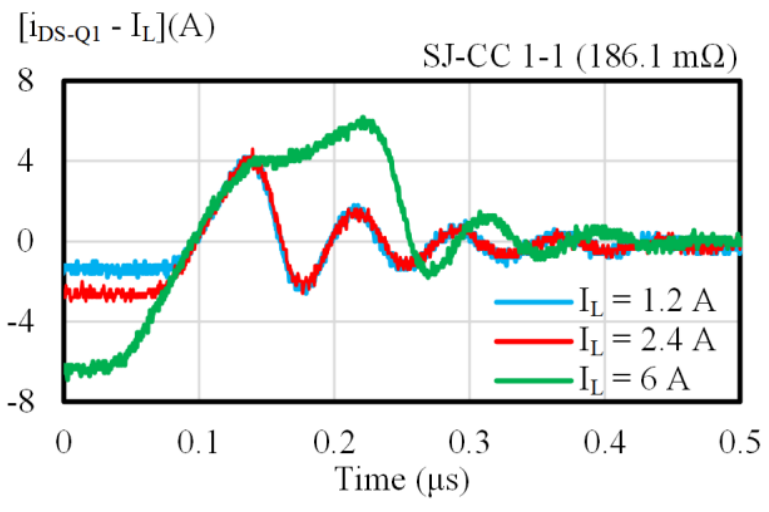

(a)

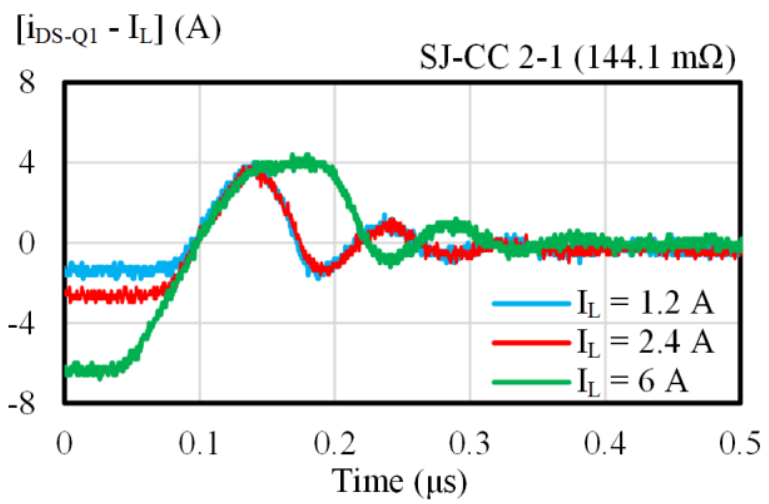

(b)

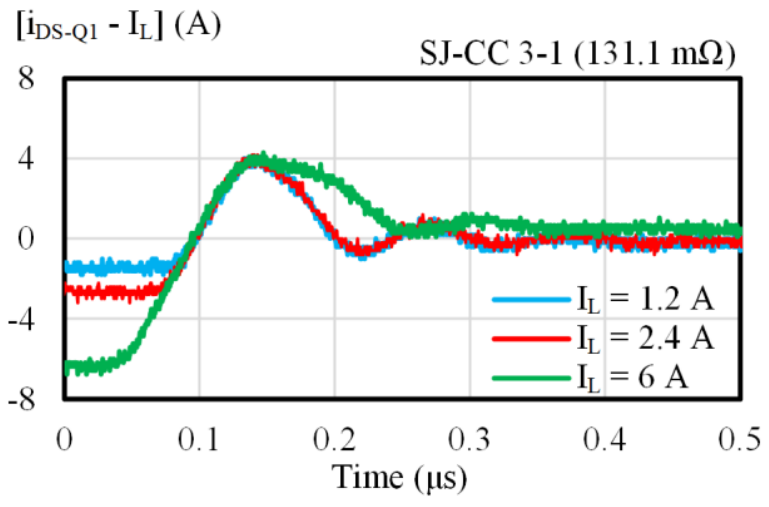

(c)

Fig. 16. Measured current waveforms for three SJ-CC designs with the same LV-FET but different SJ-FET: (a) SJ-CC 1-1. (b) SJ-CC 2-1. (c) SJ-CC 3-1.

As previously explained, the SJ-CC eliminates or mitigates QRR-D-HV and, consequently, Qoss-HV constitutes the major source of $\mathrm{Q}_{\mathrm{RR}}$. In order to demonstrate this statement, the measured $\mathrm{Q}_{\mathrm{RR}}$ will be compared to Qoss-HV. It is important to note that Qoss-Hv is evaluated by measuring experimentally Coss-HV of each SJ-FET. Fig. 17 shows and example of the Coss-HV and Qoss-HV measurement of SJ-FET 3 versus $\mathrm{V}_{\mathrm{DS}-\mathrm{HV}}$, which will help us to justify both the importance of Qoss-HV and the voltage range of the experimental boost converter.

As Fig. 17 shows, Qoss-Hv rises with $\mathrm{V}_{\mathrm{DS}-\mathrm{HV}}$ and achieves the $90 \%$ of the final value when the voltage is around $20 \mathrm{~V}$. Since the voltage across the LV-FET is close to its breakdown voltage during the off-state [15], fixing $50 \mathrm{~V}$ as the output voltage of the boost converter is enough to measure most of the Qoss-HV contribution and to characterize the RR of the DUT. Note that

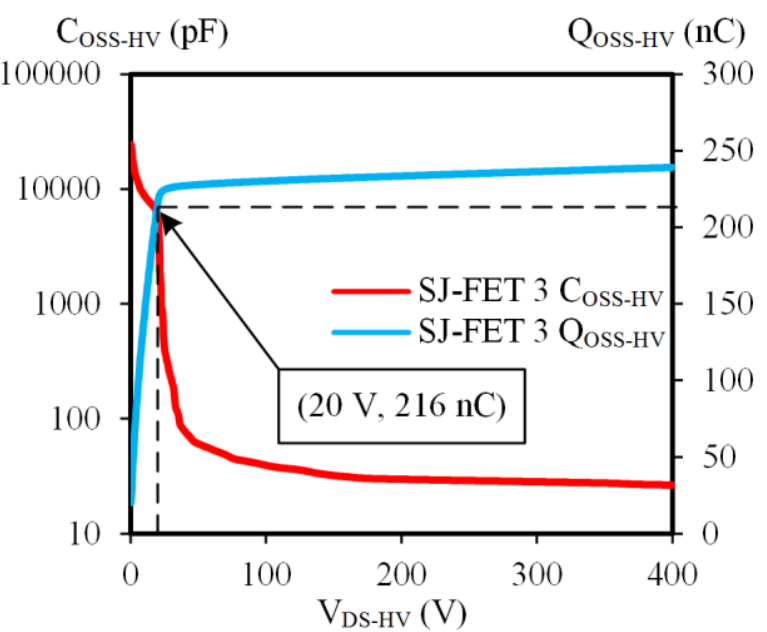

Fig. 17. Measured Coss-Hv and Qoss-Hv of the SJ-FET 3 versus $\mathrm{V}_{\text {DS-Hv. Note }}$ that Qoss-Hv achieves the $90 \%$ of its final value at $20 \mathrm{~V}$.

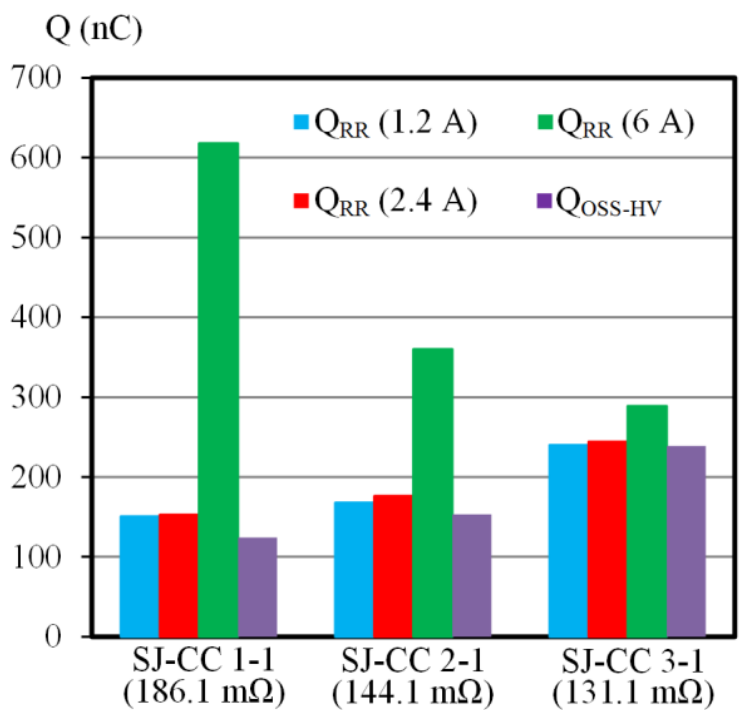

Fig. 18. $\mathrm{Q}_{\mathrm{RR}}$ measurements for three SJ-CC designs with the same LV-FET and different SJ-FETs.

since the highest breakdown voltage of the LV-FETs considered for the tests is $30 \mathrm{~V}$ (see Table II), using $50 \mathrm{~V}$ as output voltage ensures that the SJ-FET blocks a voltage equal or higher than $20 \mathrm{~V}$.

Fig. 18 shows the measured $Q_{R R}$ for three SJ-CCs with the same LV-FET (i.e., the SJ-CCs tested in Fig. 16) including the measured Qoss-Hv. It can be seen that the results match with the previous reasoning: the activation of $\mathrm{D}_{\mathrm{HV}}$ is avoided when the SJ-CC operates in state 1 (i.e., $\mathrm{I}_{\mathrm{L}}<\mathrm{I}_{\text {Lim-HV}}$ ) and, consequently, the measured $Q_{R R}$ is slightly higher than Qoss-HV. On the other hand, $\mathrm{Q}_{\mathrm{RR}}$ rises when the SJ-CC operates in state 2 (i.e., $\mathrm{I}_{\mathrm{L}}>$ $\mathrm{I}_{\text {Lim-HV }}$ ) because $\mathrm{D}_{\mathrm{HV}}$ conducts a part of $\mathrm{I}_{\mathrm{L}}$. The higher $\mathrm{Q}_{\mathrm{RR}}$ increase of SJ-CC 1-1 with respect to the $Q_{R R}$ increase of SJ-CC 2-1 in state 2 (i.e., $\mathrm{I}_{\mathrm{L}}=6 \mathrm{~A}$ ) is because $\mathrm{D}_{\mathrm{HV}}$ of the SJ-FET 1 conducts more current than $\mathrm{D}_{\mathrm{HV}}$ of SJ-FET 2. Note that $\mathrm{R}_{\mathrm{ON}-\mathrm{HV}}$ is higher in the case of the SJ-FET 1, which is translated into a higher $\mathrm{V}_{\mathrm{SD}-\mathrm{HV}}$ value for the same $\mathrm{I}_{\mathrm{L}}$ level and, therefore, higher current flowing through $\mathrm{D}_{\mathrm{HV}}$ (i.e., the $\mathrm{D}_{\mathrm{HV}}$ of SJ-FET 1 accumulates more charge carriers than that of SJ-FET 2). This reasoning is valid when $\mathrm{V}_{\gamma-\mathrm{HV}}$ is equal for both $\mathrm{SJ}-\mathrm{FET}$, which 
is a good approximation in practice.

As in the case of the static reverse conduction, the dynamic third quadrant operation barely depends on the LV-FET selected for the SJ-CC implementation. Fig. 19 shows the measured current waveforms of three SJ-CC implemented with the same SJ-FET and different LV-FETs when $\mathrm{I}_{\mathrm{L}}$ is $2.4 \mathrm{~A}$. This statement is also valid for other current levels.

\section{Comparing the RR of SJ-CCs and SJ-FETs in Standalone Configuration}

In order to evaluate the RR improvement that could be achieved by the SJ-CC, the RR behavior was also studied for SJ-FETs in standalone configuration. Four groups of transistors are considered for the experimental comparison. The first group contains the previously mentioned SJ-FETs optimized for hardswitching in standalone configuration (i.e., the ones detailed in Table I). The second group is made up of SJ-FETs with enhanced RR (i.e., irradiated SJ-FETs) in standalone configuration. The third group implements a SJ-CC using one of the irradiated SJ-FETs (IRR SJ-FET 1) in CC with the LVFET 1. Finally, the fourth group contains the SJ-FETs optimized for hard-switching from the first group in $\mathrm{CC}$ with the LV-FET 1.

Fig. 20, Fig. 21 and Fig. 22 show the measured Figures-ofMerit (FoM) $\mathrm{R}_{\mathrm{ON}} \cdot \mathrm{t}_{\mathrm{RR}}, \mathrm{R}_{\mathrm{ON}} \cdot \mathrm{I}_{\mathrm{RRM}}$ and $\mathrm{R}_{\mathrm{ON}} \cdot \mathrm{Q}_{\mathrm{RR}}$, respectively. The results at $6 \mathrm{~A}$ are omitted for the first group due to their too high self-heating in the experimental tests and possible malfunction. As expected, SJ-FETs with enhanced RR provide better results than the SJ-FETs optimized for hard-switching operation. Moreover, it can be seen that all the SJ-CCs overcome the

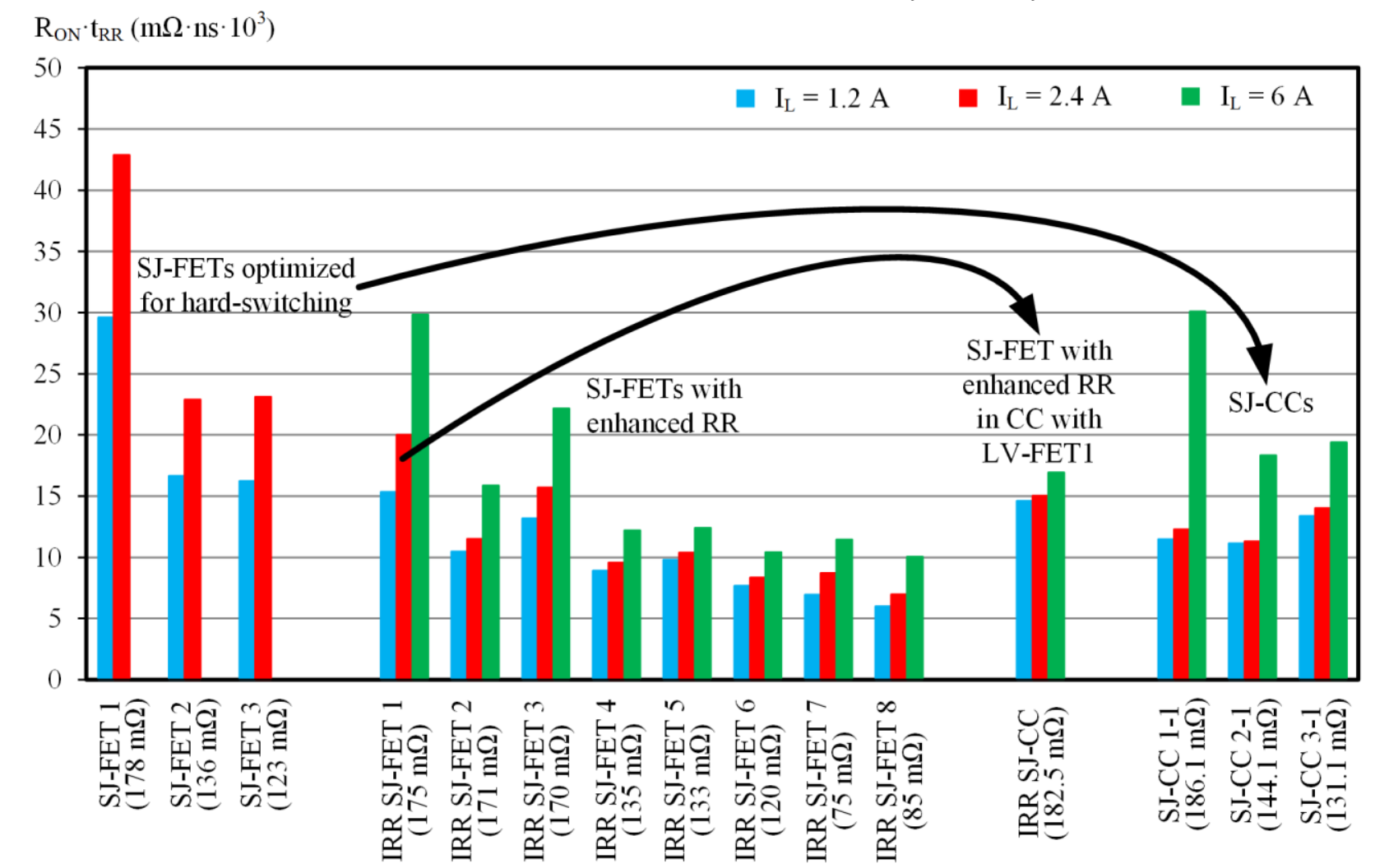

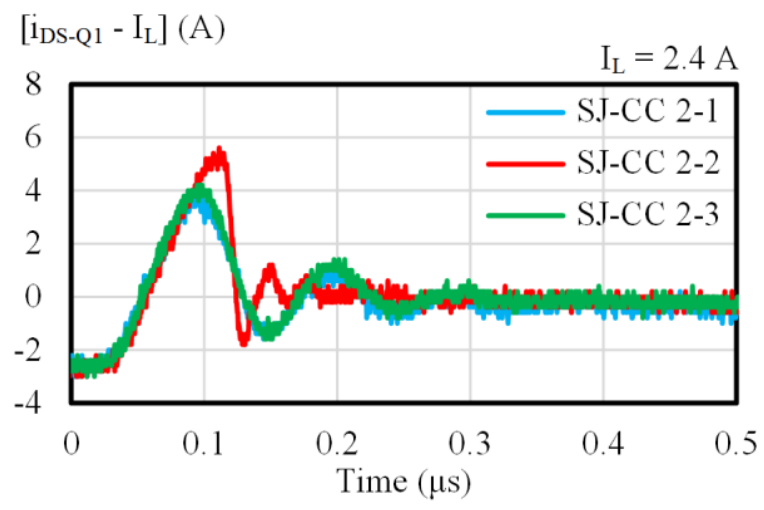

Fig. 19. Measured current waveforms for three SJ-CC designs with the same SJ-FET but different LV-FET when $\mathrm{I}_{\mathrm{L}}$ is $2.4 \mathrm{~A}$.

standalone counterparts. In addition, the SJ-CCs achieve similar or better results than the SJ-FETs with enhanced RR.

Although $\mathrm{R}_{\mathrm{ON}} \cdot \mathrm{Q}_{\mathrm{RR}}$ is the most important FoM since $\mathrm{Q}_{\mathrm{RR}}$ determines the RR losses, it is important to consider both $\mathrm{R}_{\mathrm{ON}} \cdot \mathrm{t}_{\mathrm{RR}}$ and $\mathrm{R}_{\mathrm{ON}} \cdot \mathrm{I}_{\mathrm{RRM}}$ in order to check if the $\mathrm{Q}_{\mathrm{RR}}$ changes are caused by a $t_{R R}$ change, by a $I_{R R M}$ change or by a change of both parameters. It can be seen that in the cases of the SJ-FETs optimized for hard-switching in standalone configuration and in $C C$, the rise of $Q_{R R}$ with $I_{L}$ is caused by the increase of both $t_{R R}$

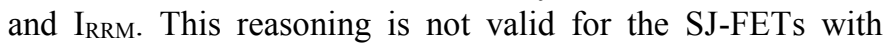
enhanced RR in standalone configuration and in CC. In these cases, the increase of $\mathrm{Q}_{\mathrm{RR}}$ that appears when $\mathrm{I}_{\mathrm{L}}$ rises from $1.2 \mathrm{~A}$ to $2.4 \mathrm{~A}$ is also caused by the increase of both $t_{R R}$ and $I_{R R M}$. However, since $\mathrm{I}_{\mathrm{RRM}}$ remains almost constant when $\mathrm{I}_{\mathrm{L}}$ rises from $2.4 \mathrm{~A}$ to $6 \mathrm{~A}$, the increase of $\mathrm{Q}_{\mathrm{RR}}$ that appears under this condition is mainly caused by the increase of $t_{R R}$.

Fig. 20. $\mathrm{R}_{\mathrm{ON}} \cdot \mathrm{t}_{\mathrm{RR}}$ FoM for different SJ-FET commercial technologies (three major SJ-FET manufacturers included). 


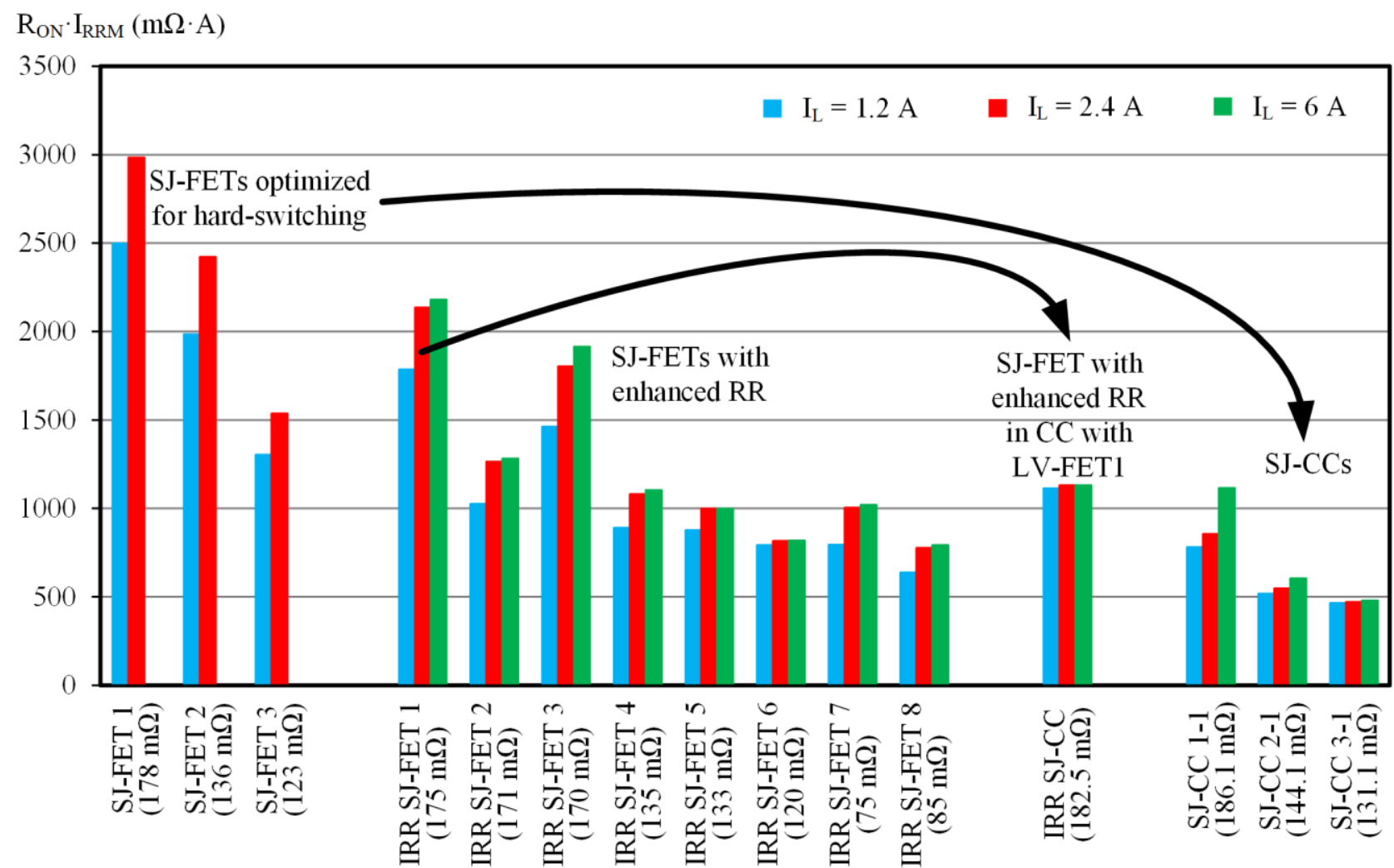

Fig. 21. $\mathrm{R}_{\mathrm{ON}} \cdot \mathrm{I}_{\mathrm{RRM}}$ FoM for different SJ-FET commercial technologies (three major SJ-FET manufacturers included).

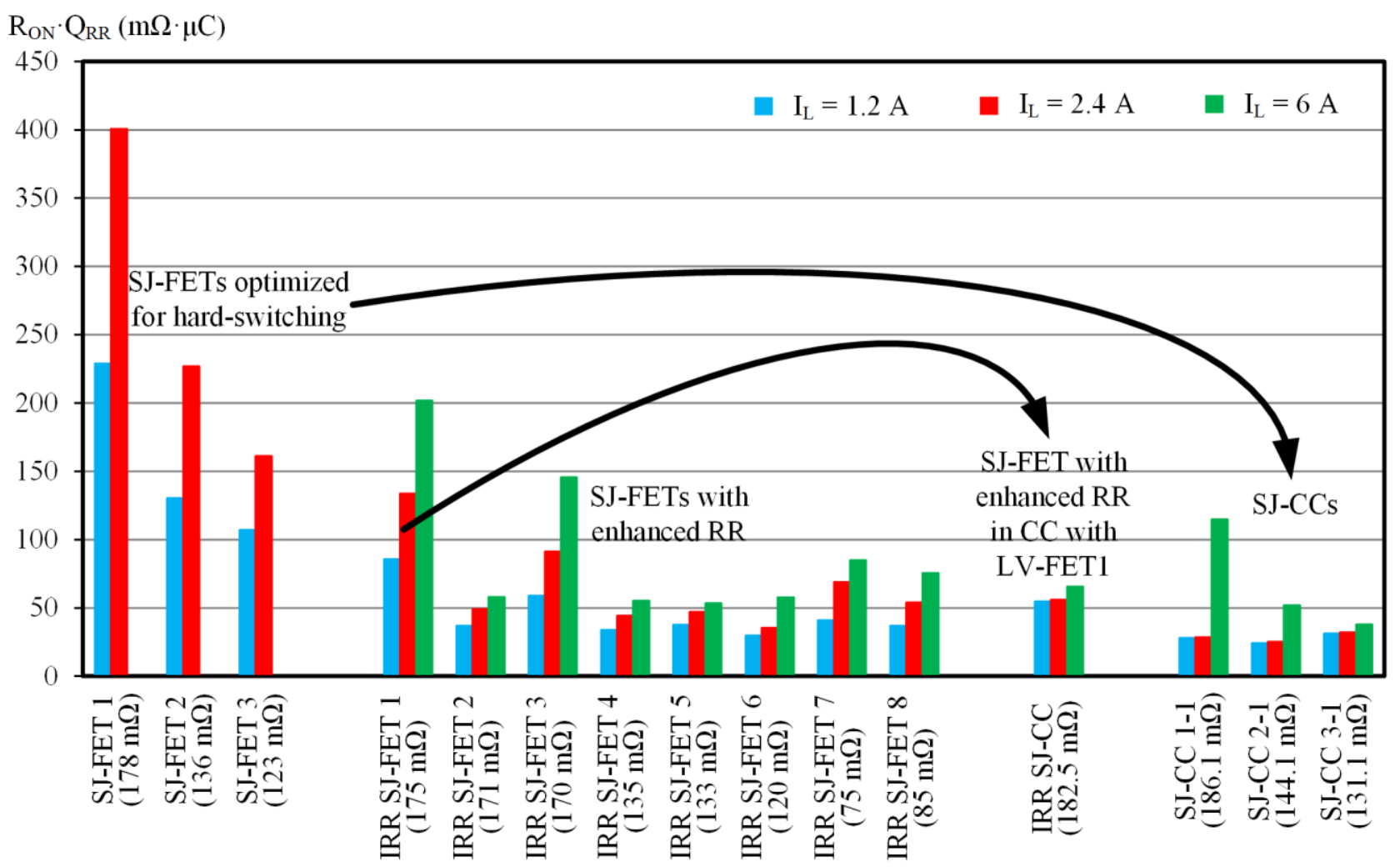

Fig. 22. $\mathrm{R}_{\mathrm{ON}} \cdot \mathrm{Q}_{\mathrm{RR}}$ FoM for different SJ-FET commercial technologies (three major SJ-FET manufacturers included).

As Fig. 22 shows, the $\mathrm{R}_{\mathrm{ON}} \cdot \mathrm{Q}_{\mathrm{RR}}$ values provided by the CCs of the fourth group are between four and eight times lower than those of the SJ-FETs from the first group (i.e., the standalone counterparts). Effectively, SJ-CC 1-1 and SJ-CC 2-1 show lower $\mathrm{R}_{\mathrm{ON}} \cdot \mathrm{Q}_{\mathrm{RR}}$ than any other SJ-FET for $1.2 \mathrm{~A}$ and $2.4 \mathrm{~A}$, whereas SJ-CC 3-1 has the best compromise of $\mathrm{R}_{\mathrm{ON}} \cdot \mathrm{Q}_{\mathrm{RR}}$ in a wider range of current. As previously explained, SJ-CC 3-1 has higher $\mathrm{I}_{\mathrm{Lim}-\mathrm{HV}}$ than SJ-CC 1-1 and SJ-CC 2-1 due to the lower 
$\mathrm{R}_{\mathrm{ON}-\mathrm{HV}}$ value of SJ-FET 3 with respect to SJ-FET 1 and SJ-FET 2. As a result, SJ-CC 3-1 avoids the $\mathrm{D}_{\mathrm{HV}}$ activation for almost all the current range of the tests $\left(\mathrm{D}_{\mathrm{HV}}\right.$ is slightly activated when $I_{L}=6 \mathrm{~A}$ ), which explains why it provides the best average result for the considered current range. However, there is a trade-off between parasitic capacitances and $\mathrm{R}_{\mathrm{ON}-\mathrm{HV}}$ in Superjunction technology: the lower the $\mathrm{R}_{\mathrm{ON}-\mathrm{HV}}$ value, the higher the parasitic capacitances. As a result, SJ-FET 3 has higher Qoss-Hv than SJFET 1 and SJ-FET 2. Since Qoss-HV is the main source of $\mathrm{Q}_{\mathrm{RR}}$ of the SJ-CCs when $\mathrm{I}_{\mathrm{L}}=1.2 \mathrm{~A}$ or $2.4 \mathrm{~A}$, SJ-CC 3-1 provides higher $\mathrm{R}_{\mathrm{ON}} \cdot \mathrm{Q}_{\mathrm{RR}}$ than SJ-CC 1-1 and SJ-CC 2-1 in this current range.

\section{Comparing the RR of SJ-CCs and Other Switch Technologies}

The target of this section is to achieve a general vision of the improvement achieved by the SJ-CC comparing it to commercial $600 \mathrm{~V}$ switches that are not based on the Superjunction technology. The switches selected for the comparison are wide bandgap devices, which offer great dynamic reverse conduction behavior. In this way, the results achieved by the SJ-CC 3-1 are compared to those of a GaN HEMT in CC (290 $\mathrm{m} \Omega)$, a normally-off $\mathrm{GaN}$ transistor (100 $\mathrm{m} \Omega$ ) and a SiC Schottky diode (dynamic resistance of $110 \mathrm{~m} \Omega$ ).

Fig. 23 shows the measured $R_{O N} \cdot t_{R R}, R_{O N} \cdot I_{R R M}$ and $\mathrm{R}_{\mathrm{ON}} \cdot \mathrm{Q}_{\mathrm{RR}}$ of the considered power switches. It can be seen that the $\mathrm{SiC}$ Schottky diode provides the best results, while the SJCC 3-1 provides the worst ones. It is important to highlight that although the normally-off $\mathrm{GaN}$ transistor provides lower $\mathrm{R}_{\mathrm{ON}} \cdot \mathrm{Q}_{\mathrm{RR}}$ than the GaN-CC, the last one achieves lower $\mathrm{R}_{\mathrm{ON}} \cdot \mathrm{t}_{\mathrm{RR}}$. Focusing the attention on the $\mathrm{R}_{\mathrm{ON}} \cdot \mathrm{Q}_{\mathrm{RR}}$ results, it can be seen that the SJ-CC 3-1 achieves a results around eight times higher than the GaN-CC.

It can be concluded that although the SJ-CC reduces $\mathrm{Q}_{\mathrm{RR}}$ with respect to the standalone counterpart by avoiding or mitigating QRR-D-HV, the RR caused by the charge stored in the SJ-FET output capacitance (i.e., Qoss-HV) is so high that achieving the low RR levels of wide bandgap switches is not possible.

\section{CONCLUSIONS}

Although SJ-FETs provide great performance when they operate in the first quadrant and under hard-switching conditions, using them in SR does not offer good results. The reason is that their body-diode provides low performance, and since it is activated during the dead-times, it causes a RR effect that jeopardizes the third quadrant operation. Differently from the standalone configuration, the SJ-CC avoids or mitigates the activation of this body-diode by keeping the SJ-FET in on-state when the transistor operates in the third quadrant. Evaluating the $R R$ in terms of $t_{R R}, I_{R R M}$ and $Q_{R R}$, enables the comparison of the SJ-CC with SJ-FETs in standalone configuration, GaN$\mathrm{CCs}$, normally-off $\mathrm{GaN}$ transistors and $\mathrm{SiC}$ Schottky diodes. The results show that a SJ-CC always improve the third quadrant performance with respect to the same SJ-FET in standalone configuration. Moreover, the results provided by SJCCs are similar or better that those of irradiated SJ-FETs in standalone configuration. Focusing the attention on the

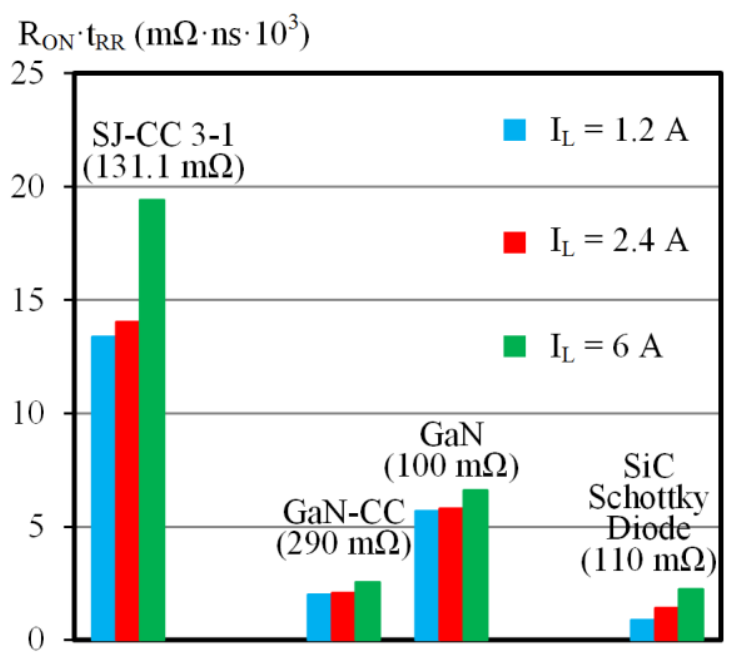

(a)

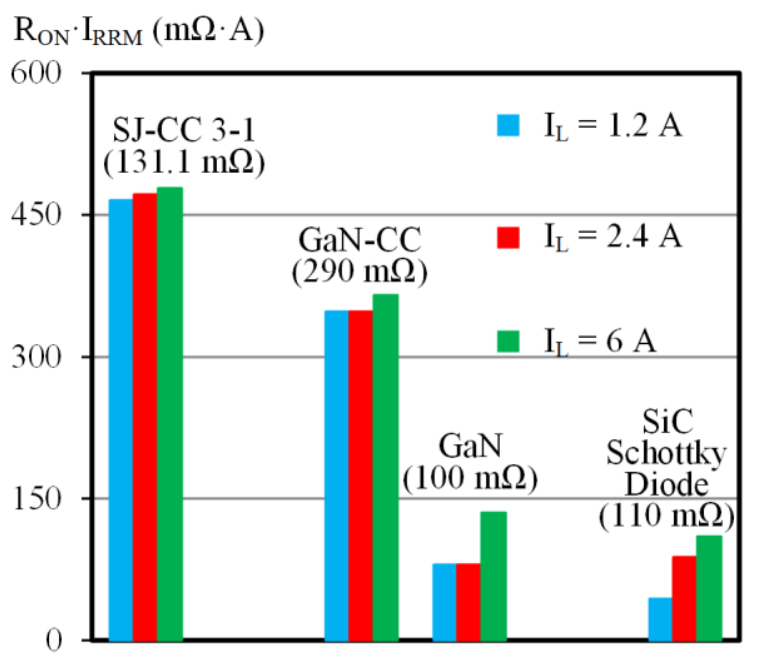

(b)

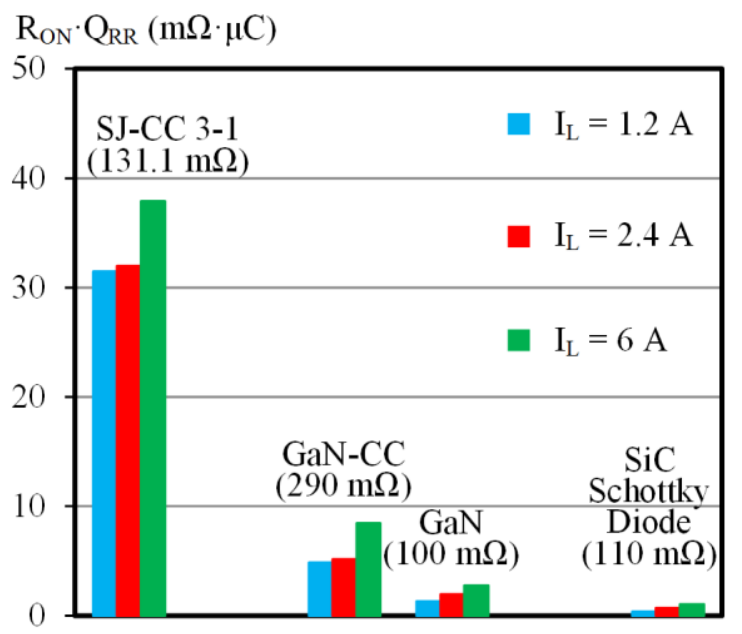

(c)

Fig. 23. Comparison between the RR of the SJ-CC 3-1 and switches that are not based on Superjunction technology: (a) $R_{\mathrm{ON}} \cdot t_{\mathrm{RR}}$ ( (b) $R_{\mathrm{ON}} \cdot I_{\mathrm{RRM}} \cdot$ (c) $R_{\mathrm{ON}} \cdot \mathrm{Q}_{\mathrm{RR}}$.

comparison with the previously mentioned wide bandgap devices, it can be concluded that the SJ-CC provides a $\mathrm{R}_{\mathrm{ON}} \cdot \mathrm{Q}_{\mathrm{RR}}$ value around eight times higher than the GaN-CC. Taking into account the good switching behavior that the SJ-CC showed in previous works, this configuration constitutes a power transistor suitable for high switching frequency, high current 
and SR that keeps the reliability, the maturity and the good relationship between performance and cost of the SJ-FET technology.

\section{ACKNOWLEDGMENT}

This work has been supported by the Spanish Government under Project MINECO-17-DPI2016-75760-R, the scholarship FPU14/03268 and the Principality of Asturias under the Project SV-PA-17-RIS3-4 and the European Regional Development Fund (ERDF) grants.

\section{REFERENCES}

[1] G. Deboy, N. Marz, J. P. Stengl, H. Strack, J. Tihanyi and H. Weber, "A new generation of high voltage MOSFETs breaks the limit line of silicon," International Electron Devices Meeting 1998. Technical Digest (Cat. No.98CH36217), San Francisco, CA, USA, 1998, pp. 683-685.

[2] T. Fujihira and Y. Miyasaka, "Simulated superior performances of semiconductor superjunction devices," Power Semiconductor Devices and ICs, 1998. ISPSD 98. Proceedings of the 10th International Symposium on, Kyoto, 1998, pp. 423-426.

[3] L. Lorenz, G. Deboy, A. Knapp and M. Marz, "COOLMOS ${ }^{\mathrm{TM}}$-a new milestone in high voltage power MOS," Power Semiconductor Devices and ICs, 1999. ISPSD '99. Proceedings., The 11th International Symposium on, Toronto, Ont., 1999, pp. 3-10.

[4] R. Ng, F. Udrea, K. Sheng and G. A. J. Amaratunga, "A study of the CoolMOS integral diode: analysis and optimization," 2001 International Semiconductor Conference. CAS 2001 Proceedings (Cat. No.01TH8547), Sinaia, 2001, pp. 461-464 vol.2.

[5] R. K. Burra and K. Shenai, "CoolMOS integral diode: a simple analytical reverse recovery model," Power Electronics Specialist Conference, 2003. PESC '03. 2003 IEEE 34th Annual, 2003, pp. 834-838 vol.2.

[6] E. Persson, "Practical application of $600 \mathrm{~V}$ GaN HEMTs in power electronics," Applied Power Electronics Conference and Exposition (APEC), Professional Education Seminar, 2015.

[7] U. Mishra, "Compound semiconductors; $\mathrm{GaN}$ and $\mathrm{SiC}$, separating fact from fiction in both research and business", Applied Power Electronics Conference and Exposition (APEC), Plenary Session, 2013.

[8] D. C. Sheridan, D. Y. Lee, A. Ritenour, V. Bondarenko, J. Yang and C. Coleman, "Ultra-low loss 600V - 1200V GaN power transistors for high efficiency applications," PCIM Europe 2014; International Exhibition and Conference for Power Electronics, Intelligent Motion, Renewable Energy and Energy Management; Proceedings of, Nuremberg, Germany, 2014, pp. 1-7.

[9] A. Bhalla, X. Li, and J. Bendel, "Switching behaviour of USCi's SiC cascodes,” Bodo's Power Systems, March 2015, Jun. 2015.

[10] ON Semiconductor, "Power GaN cascode transistor $600 \mathrm{~V}, 290 \mathrm{~m} \Omega$," NTP8G202N datasheet, May 2015.

[11] Artur Seibt, "Performance comparisons of SiC transistors, GaN cascodes and $\mathrm{Si}$ - Coolmos in SMPS," Bodo's Power Systems, March 2015.

[12] Artur Seibt, "Cascode switches - the fast route to higher efficiency," Bodo's Power Systems, May 2015.

[13] J. Rodriguez, J. Roig, A. Rodriguez, D. G. Lamar and F. Bauwens, "Modeling the switching behaviour of SuperJunction MOSFETs in cascode configuration with a low voltage silicon MOSFET," 2016 IEEE 17th Workshop on Control and Modeling for Power Electronics (COMPEL), Trondheim, 2016, pp. 1-8.

[14] J. Rodriguez, A. Rodriguez, I. Castro, D. G. Lamar, J. Roig and F. Bauwens, "SuperJunction cascode, a configuration to break the silicon switching frequency limit", 2016 IEEE Energy Conversion Congress and Exposition (ECCE), Milwaukee, WI, 2016.

[15] J. Rodríguez, J. Roig, A. Rodríguez, D. G. Lamar and F. Bauwens, "Evaluation of Superjunction MOSFETs in cascode configuration for hard-switching operation," in IEEE Transactions on Power Electronics, vol. 33, no. 8, pp. 7021-7037, Aug. 2018.

[16] J. Rodriguez, A. Rodriguez, D. G. Lamar, J. Roig and F. Bauwens, "Reducing Qrr in high-voltage Superjunction MOSFETs by using the cascode configuration," 2017 IEEE Applied Power Electronics Conference and Exposition (APEC), Tampa, FL, 2017, pp. 1970-1977.

[17] P. Haaf and J. Harper, "Understanding diode reverse recovery and its effect on switching losses", Proc. Fairchild Power Semin., pp. A23-A33, 2007.

[18] H. Kim, T. M. Jahns and G. Venkataramanan, "Minimization of reverse recovery effects in hard-switched inverters using CoolMOS power switches," Conference Record of the 2001 IEEE Industry Applications Conference. 36th IAS Annual Meeting (Cat. No.01CH37248), Chicago, IL, USA, 2001, pp. 641-647 vol.1.

[19] D. Polenov, T. Reiter, R. Baburske, H. Probstle and J. Lutz, "The influence of turn-off dead time on the reverse-recovery behaviour of synchronous rectifiers in automotive DC/DC-converters," 2009 13th European Conference on Power Electronics and Applications, Barcelona, 2009, pp. 1-8.

[20] T. Reiter, D. Polenov, H. Probstle and H. G. Herzog, "Optimization of PWM dead times in DC/DC-converters considering varying operating conditions and component dependencies," 2009 13th European Conference on Power Electronics and Applications, Barcelona, 2009, pp. 1-10.

[21] D. DeWitt, C. Brown and S. Robertson, "The pinch-off circuit: reducing noise and component stresses by eliminating body diode conduction in synchronous rectifiers," APEC 07 - Twenty-Second Annual IEEE Applied Power Electronics Conference and Exposition, Anaheim, CA, USA, 2007, pp. 1531-1536.

[22] D. B. DeWitt, C. D. Brown, and S. M. Robertson, "System and method for reducing body diode conduction," U.S. Patent 7508 175, Mar. 24, 2009.

[23] C. D. Brown and B. Sarlioglu, "Reducing switching losses in BLDC motor drives by reducing body diode conduction of MOSFETs," in IEEE Transactions on Industry Applications, vol. 51, no. 2, pp. 1864-1871, March-April 2015.

[24] N. McNeill, P. Anthony, B. H. Stark and P. H. Mellor, "Efficient singlephase grid-tie inverter for small domestic photovoltaic scheme," 6th IET International Conference on Power Electronics, Machines and Drives (PEMD 2012), Bristol, 2012, pp. 1-6.

[25] X. Cheng, X. M. Liu, J. K. O. Sin and B. W. Kang, "Improving the CoolMS ${ }^{\mathrm{TM}}$ body-diode switching performance with integrated Schottky contacts," Power Semiconductor Devices and ICs, 2003. Proceedings. ISPSD '03. 2003 IEEE 15th International Symposium on, 2003, pp. 304307.

[26] M. Schmitt et al., "A comparison of electron, proton and helium ion irradiation for the optimization of the CoolMOS ${ }^{\mathrm{TM}}$ body diode," Proceedings of the 14th International Symposium on Power Semiconductor Devices and Ics, 2002, pp. 229-232.

[27] J. Zhu, L. Zhang, W. F. Sun, et al. Analysis of the electrical characteristics of $600 \mathrm{Vclass}$ electron irradiated fast recovery superjunction VDMOS. Solid-state Electron 2013;80:38-44.

[28] W. Saito, S. Ono and H. Yamashita, "Influence of carrier lifetime control process in superjunction MOSFET characteristics," 2014 IEEE 26th International Symposium on Power Semiconductor Devices \& IC's (ISPSD), Waikoloa, HI, 2014, pp. 87-90.

[29] N. McNeill, R. Wrobel and P. H. Mellor, "Synchronous rectification technique for high-voltage single-ended power converters," 2010 IEEE Energy Conversion Congress and Exposition, Atlanta, GA, 2010, pp. 264-271.

[30] N. McNeill, X. Yuan and P. Anthony, "High-efficiency NPC multilevel converter using Super-Junction MOSFETs," in IEEE Transactions on Industrial Electronics, vol. 63, no. 1, pp. 25-37, Jan. 2016.

[31] A. Hopkins, P. P. Proynov, N. McNeill, B. H. Stark and P. Mellor, "Achieving efficiencies exceeding $99 \%$ in a Super-Junction $5 \mathrm{~kW}$ DCDC converter power stage through the use of an energy recovery snubber and dead time optimization," in IEEE Transactions on Power Electronics, vol. PP, no. 99, pp. 1-1.

[32] W. Yu and J. S. Lai, "Ultra high efficiency bidirectional dc-dc converter with multi-frequency pulse width modulation," 2008 Twenty-Third Annual IEEE Applied Power Electronics Conference and Exposition, Austin, TX, 2008, pp. 1079-1084.

[33] S. Y. Park, P. Sun, W. Yu and J. S. Lai, "Performance evaluation of high voltage super junction MOSFETs for zero-voltage soft-switching inverter applications," 2010 Twenty-Fifth Annual IEEE Applied Power 
Electronics Conference and Exposition (APEC), Palm Springs, CA, 2010, pp. 387-391.

[34] Y. F. Huang, Y. Konishi and W. J. Ho, "Series resonant type softswitching grid-connected single-phase inverter employing discontinuous-resonant control applied to photovoltaic AC module," 2011 Twenty-Sixth Annual IEEE Applied Power Electronics Conference and Exposition (APEC), Fort Worth, TX, 2011, pp. 989-994.

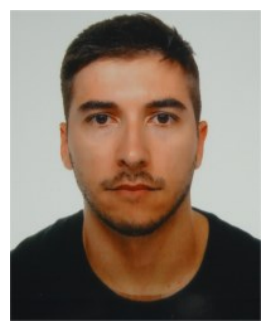

Juan Rodríguez (S'15) was born in Avilés, Spain, in 1991. He received the M.Sc. degree in telecommunication engineering from the University of Oviedo, Spain, in 2014, where he is currently working towards the Ph.D. degree in electrical engineering.

His research interests are focused on high-frequency DC-DC power converters, wide bandgap semiconductors and LED drivers for visible light communication.

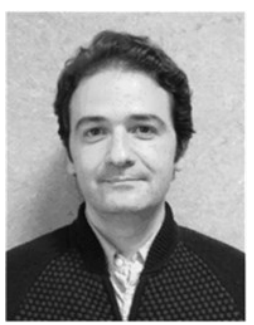

Diego G. Lamar (M'08) was born in Zaragoza, Spain, in 1974. He received the M.Sc. degree, and the Ph.D. degree in Electrical Engineering from the University of Oviedo, Spain, in 2003 and 2008, respectively.

In 2003 and 2005 he became a Research Engineer and an Assistant Professor, respectively at the University of Oviedo. Since September 2011, he has been an Associate Professor.

His research interests are focused in switching-mode power supplies, converter modelling, and power-factor-correction converters.

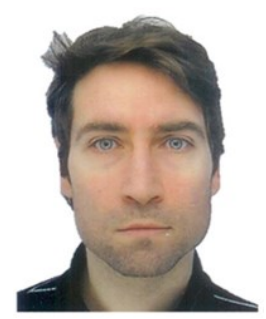

Jaume Roig received the B.S. degree in physics and the Ph.D. degree in microelectronics engineering from the Universitat Autónoma de Barcelona, Bellaterra, Spain, in 1999 and 2004, respectively.

From 2000 to 2005, he was with the National Research Council laboratories in Barcelona performing research in new device concepts for silicon-on-insulator smart power technologies. He joined LAAS/CNRS, Toulouse, France, in 2005 to continue his investigations in to discrete and integrated semiconductor devices. He joined ON Semiconductor Belgium, Oudenaarde, Belgium, in 2006, where he is currently working on the design and the development of silicon and GaN power technologies. His main topic of interest is the interaction between device and circuit for specialized optimization of power switches. He has authored or coauthored more than 125 scientific articles published in international and conference proceedings, and he also holds 15 issued and 5 pending patents.

Dr. Roig regularly serves as a Reviewer for numerous IEEE journals and conferences.

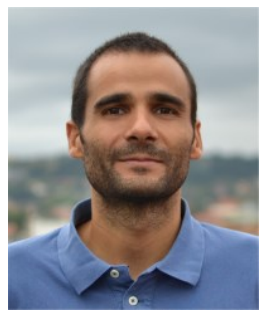

Alberto Rodríguez (S'07, M'14) was born in Oviedo, Spain, in 1981. He received the M.Sc. degree in telecommunication engineering in 2006 and the $\mathrm{Ph}$. D. degree in electrical engineering in 2013, both from the University of Oviedo, Gijon, Spain.

Since 2006, he has been a Researcher in the Power Supply System Group and an Assistant Professor in the Department of Electrical and Electronic Engineering at the University of Oviedo.

His research interests include multiple ports power supply systems, bidirectional DC-DC power converters and wide band gap semiconductors.

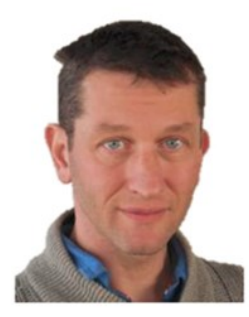

Filip Bauwens received the M.Sc. degree in applied physics and the Ph.D. degree in nuclear physics from the University of Ghent, Ghent, Belgium, in 1995 and 2000, respectively.

In 2001, he joined ON Semiconductor Belgium, Oudenaarde, Belgium. His focus was on the development of smart power technologies, in particular, on hot-carrier and other degradation phenomena. He currently manages a team of device engineers mainly involved in the prestudy of new smart power technologies and discrete power devices, including process specification, assessment of electrical and degradation behavior, their role in applications, and more detailed (3-D) technology computer-aided design studies. His main activities currently are focused on investigating the interaction between silicon and GaN power devices (15-650 V rated BVDSS) and their switching circuits to optimize the devices for applications. He is the author or coauthor of more than 50 international journal and conference proceedings papers and the holder of several patents. 